\title{
Thoracic endovascular repair of chronic type B aortic dissection: a systematic review
}

\author{
Michael L. Williams ${ }^{1,2,3}$, Madeleine de Boer ${ }^{4}$, Bridget Hwang ${ }^{2}$, Bruce Wilson ${ }^{2}$, John Brookes ${ }^{2,5}$, \\ Nicholas McNamara ${ }^{6}$, David H. Tian ${ }^{7}$, Timothy Shiraev ${ }^{4}$, Ourania Preventza ${ }^{8,9}$ \\ ${ }^{1}$ Department of Cardiothoracic Surgery, John Hunter Hospital, Newcastle, Australia; ${ }^{2}$ The Collaborative Research (CORE) Group, Macquarie \\ University, Sydney, Australia; ${ }^{3}$ School of Medicine and Public Health, University of Newcastle, Newcastle, Australia; ${ }^{4}$ Department of Vascular \\ Surgery, Royal Prince Alfred Hospital, Sydney, Australia; ${ }^{5}$ Department of Cardiothoracic Surgery, University Hospital Geelong, Geelong, Australia; \\ ${ }^{6}$ Department of Cardiothoracic Surgery, Royal Prince Alfred Hospital, Sydney, Australia; ${ }^{7}$ Department of Anaesthesia and Perioperative Medicine, \\ Westmead Hospital, Sydney, Australia; ${ }^{8}$ Division of Cardiothoracic Surgery, Michael E. DeBakey Department of Surgery, Baylor College of \\ Medicine, Houston, Texas, USA; ${ }^{9}$ Department of Cardiovascular Surgery, Texas Heart Institute, Houston, Texas, USA \\ Correspondence to: Dr. Michael L. Williams. Department of Cardiothoracic Surgery, John Hunter Hospital, Newcastle, NSW 2305, Australia. \\ Email: dr.michaelwilliams.au@gmail.com.
}

Background: At present, the optimal management strategy for chronic type B aortic dissection (CTBAD) remains unknown, as equipoise remains regarding medical management versus endovascular treatment versus open surgery. However, the results over recent years of thoracic endovascular aortic repair (TEVAR) in CTBAD appear promising. The aim of this systematic review was to provide a comprehensive analysis of the available data reporting outcomes and survival rates for TEVAR in CTBAD.

Methods: Electronic searches of six databases were performed from inception to April 2021. All studies reporting outcomes, specifically 30-day mortality rates, for endovascular repair of CTBAD were identified. Relevant data were extracted, and a random-effects meta-analysis of proportions or means was performed to aggregate the data. Survival data were pooled using data derived from original Kaplan-Meier curves, which allows reconstruction of individual patient data.

Results: Forty-eight studies with 2,641 patients were identified. Early (<30 days) all-cause and aorticrelated mortality rates were low at $1.6 \%$ and $0.5 \%$, respectively. Incidence of retrograde type A dissection in the post-operative period was only $1.4 \%$. There were also low rates of cerebrovascular accidents and spinal cord injury (1.1\% and $0.9 \%$, respectively). Late follow-up all-cause mortality was $8.0 \%$, however, late aorticrelated mortality was only $2.4 \%$. Reintervention rates were $10.1 \%$ for endovascular and $6.7 \%$ for surgical reintervention. Pooled rates of overall survival at 1-, 3-, 5- and 10-year were $91.5 \%, 84.7 \%, 77.7 \%$ and $56.3 \%$, respectively.

Conclusions: The significant heterogeneity in the available evidence and absence of consensus reporting standards are important considerations and concern when interpreting the data. Evaluation of the evidence suggests that TEVAR for CTBAD is a safe procedure with low rates of complications. However, the optimal treatment strategy for CTBAD remains debatable and requires further research. Evidence from high-quality registries and clinical trials are required to address these challenges.

Keywords: Chronic type B aortic dissection (CTBAD); thoracic endovascular aortic repair (TEVAR); descending thoracic aorta

Submitted Sep 07, 2021. Accepted for publication Oct 04, 2021.

doi: 10.21037/acs-2021-taes-25

View this article at: https://dx.doi.org/10.21037/acs-2021-taes-25 


\section{Introduction}

Aortic disease, and more specifically aortic dissection, comprises a significant disease burden, occurring twice as often in males compared with females and frequently occurring in patients aged between $50-70$ years $(1,2)$. With an incidence estimated at 5-30 per million per year, $20 \%$ of patients with aortic dissection die before reaching hospital, with a further $30 \%$ of those who do reach tertiary centres dying during their hospital admission $(1,3,4)$. In light of this, there has been increased interest in the management of aortic dissections, particularly with the shift towards endovascular management as endovascular graft technology continues to evolve.

Disease processes, such as atherosclerosis, chronic hypertension, or the presence of genetic conditions (such as vascular Ehlers-Danlos or Marfan syndromes) that alter the integrity of the elastic or muscular components of the aortic wall, predispose patients to the development of aortic dissection (4). Whilst this pathology can be classified using multiple systems, one of the most common classifications is the Stanford classification, which describes dissections as either Type A, with the entry tear proximal to the ostium of the left subclavian artery, or Type B, with the entry tear distal to the ostium of the left subclavian artery (4). Whilst most Type A aortic dissections are surgical emergencies and require open replacement of the ascending aorta with or without aortic root or arch replacement (5), uncomplicated Type B aortic dissections have classically been managed medically with strict blood pressure and heart rate control to reduce pulse pressure, statins and lifestyle modification $(6,7)$. Surgical management has classically been reserved for complicated Type B dissections (those associated with rupture or malperfusion syndromes), via open surgical repair or thoracic endovascular aortic repair (TEVAR) $(8-10)$. However, it is estimated that $25-50 \%$ of patients with acute Type $\mathrm{B}$ aortic dissections who are managed medically will undergo aneurysmal degeneration of the dissected segment and require surgical repair, either via open or endovascular methods, during the chronic phase of their disease process $(3,10)$.

There is ongoing debate within the literature surrounding the management of chronic type $B$ aortic dissection (CTBAD) and whether optimal medical therapy or the use of TEVAR is most effective in the management of this pathology (9-11). Historically, the definition of chronicity in type $\mathrm{B}$ aortic dissection has been after 14 days have elapsed from symptom onset. This classification is based on the high rate of mortality (up to $70 \%$ ) in aortic dissection within the first 2 weeks of onset (12). In recent years, a third "sub-acute" category (between 2 weeks and 3 months) has been proposed in the classification system, as the risk of death remains high in the first 3 months (13). CTBADs are associated with a risk of rupture, with recent guidelines suggesting that this risk increases with aneurysmal dilatation $(2,8,10)$. Rates of aortic rupture have been quoted as high as $28.6 \%$ in aortic diameters of up to $6.4 \mathrm{~cm}(8)$. As such, aneurysmal dilatation and rapid growth of aneurysms are one of the most frequent indications for the treatment of CTBAD $(2,3)$. Open surgical repair has several significant disadvantages compared to endografting, including the necessity for a posterolateral thoracotomy or thoracoabdominal incision depending on the extent of the required repair, single lung ventilation, full or partial cardiopulmonary bypass, and possible circulatory arrest and hypothermia (4). Subsequently, the use of TEVAR in CTBAD has had an increased focus over the past decade.

This systematic review sought to provide a comprehensive analysis of the currently available literature to determine early outcomes, reintervention rates and mid- or long-term survival rates for endovascular repair of CTBAD.

\section{Methods}

\section{Literature search strategy}

Six electronic databases were used to perform the literature search including Ovid MEDLINE, EMBASE, Cochrane Central Register of Controlled Trials, Cochrane Database of Systematic Reviews (CDSR), SCOPUS, and Database of Abstracts of Review of Effectiveness (DARE). These databases were searched from date of inception to $26^{\text {th }}$ April 2021. The search strategy included a combination of keywords and Medical Subject Headings (MeSH) including "Aorta" AND "Dissection" AND "Chronic" AND "Endovascular Procedures" OR "Endovascular repair" OR "TEVAR". Predefined selection criteria were used to assess all relevant articles that were identified. Our methods adhered to the guidelines set forth in the Preferred Reporting Items for Systematic Reviews and Meta-Analyses: The PRISMA Statement (14). Two reviewers (MLW and $\mathrm{MDB}$ ) independently screened the title and abstract of all identified records in the search. Where the title/abstract provided insufficient detail to determine study relevance, a full-text copy of the article was retrieved for review. The reference lists of selected studies were reviewed manually 
to identify any extra relevant studies not identified in the electronic search.

\section{Selection criteria}

Studies were eligible for inclusion in this systematic review if they included a patient population who underwent TEVAR for Chronic Stanford type B/DeBakey type III aortic dissection. Chronicity of dissection for this systematic review was defined as greater than 2 weeks following symptomatic presentation or documentation of an intimal entry tear. Studies that described mixed populations of acute and chronic dissections without separate patient or outcome data were deemed ineligible for inclusion. Studies had to report the primary outcome of interest (see below) and have a minimum CTBAD cohort greater than ten patients to be eligible for inclusion. Residual CTBAD post previous Type $A$ and open ascending aorta surgical repair were included due to a number of studies reporting mixed populations with no separate data/outcomes for these cohorts. Cases that involved the abdominal aorta only were excluded. Hybrid (open and endovascular) procedures or branched and/or fenestrated endovascular repair for CTBAD were excluded. When trials/registries/institutions published duplicate studies with extended length of follow-up or larger study populations, the most updated and complete study was included. Included studies were limited to those in English and only involving human subjects. Abstracts, case reports, conference presentations, editorials and reviews were excluded.

\section{Outcomes of interest}

The primary outcome of interest was in-hospital/30-day mortality. Secondary outcomes of interest included mid- to long-term survival rates and other post-operative outcomes, including aortic related mortality, rupture, retrograde type A dissection, cerebrovascular accident (CVA) and spinal cord injury (SCI).

\section{Data extraction and critical appraisal}

Two independent reviewers ( $\mathrm{BH}$ and $\mathrm{BW}$ ) extracted data directly from publication texts, tables and figures. A third reviewer (MLW) independently reviewed and confirmed all extracted data. Differences of opinions between the two main reviewers $(\mathrm{BH}$ and $\mathrm{BW})$ were resolved through means of discussion and consensus, including primary investigator (MLW) where necessary. Attempts were made to clarify insufficient or indistinct data from corresponding authors of included studies where required. Outcome data was extracted in a manner in which each study was effectively treated as a case series regardless of actual study design, and therefore a critical appraisal of the quality of each individual included study was not performed.

\section{Statistical analysis}

A meta-analysis of proportions or means were performed for categorical and continuous variables, as appropriate. A random effects model was used to account for differing center/surgeon experience, different endoprostheses used, and different operative and management protocols across the included studies. To facilitate this statistical pooling, means and standard deviations were calculated from the median (with range or interquartile range), where reported, using the methods described by Wan and colleagues (15). Pooled data are presented as n (\%) with $95 \%$ confidence intervals (CI). For outcome data, heterogeneity amongst studies was assessed using the $\mathrm{I}^{2}$ statistic. Thresholds for $\mathrm{I}^{2}$ values were considered as low, moderate and high heterogeneity as $0-49 \%, 50-74 \%$ and $\geq 75 \%$, respectively (16). Meta-analysis of proportions or means were performed using Stata (version 17.0, StataCorp, Texas, USA).

Survival data was calculated from aggregation of Kaplan-Meier survival data from included studies, where reported, using the methods described by Guyot and colleagues (17). Aggregation of this data was performed by reconstructing individual patient data from digitized Kaplan-Meier survival curves and patient number-at-risk data. The reconstructed individual patient data were then pooled and used to generate an aggregated survival curve. Digitization of source Kaplan Meier curves was performed using DigitizeIt (version 2.5.9, Braunschweig, Germany) and survival analysis was performed using $\mathrm{R}$ (version 3.5.2, R Foundation for Statistical Computing, Vienna, Austria).

\section{Results}

The literature search identified a total 915 studies (Figure 1). An additional nine articles were identified on manual searches of reference lists. After exclusion of duplicates or irrelevant studies, 97 articles were deemed appropriate to undergo full-text review. Forty-eight studies with a total 

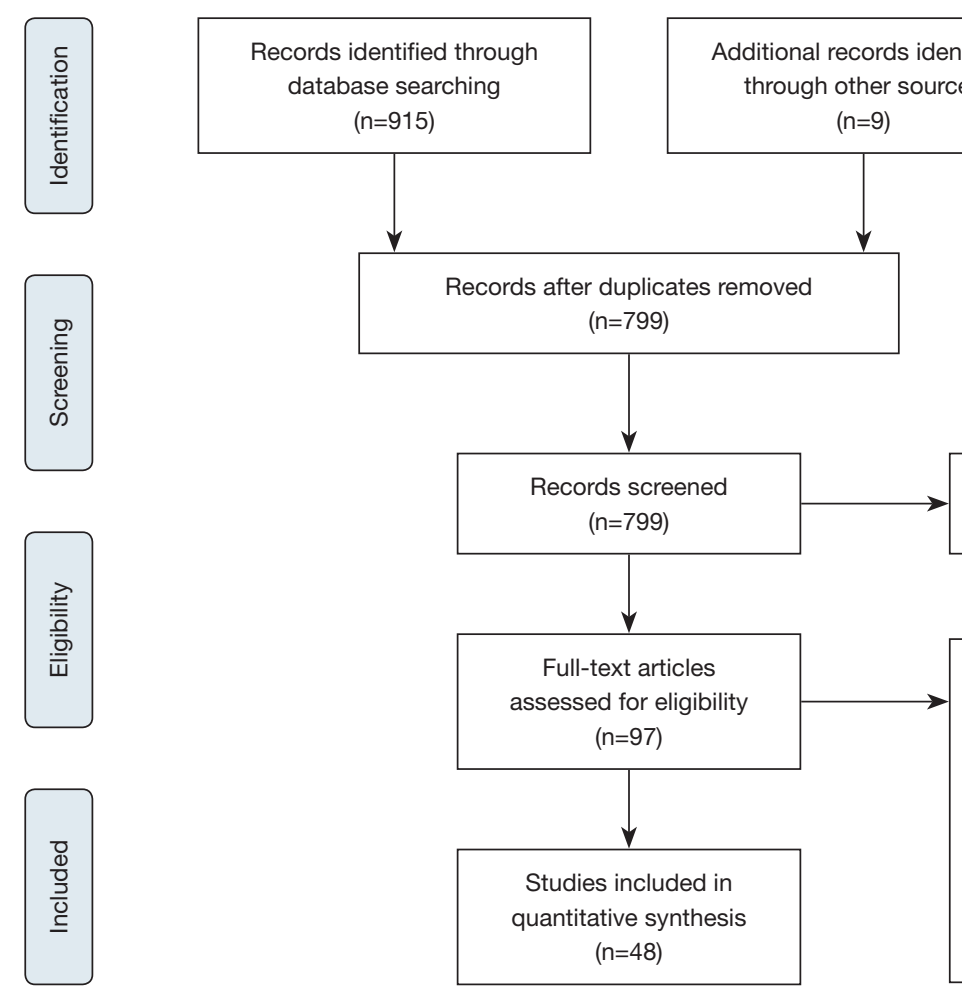

Records excluded $(n=702)$

Figure 1 PRISMA flow-chart summarizing the search strategy for relevant publications.

of 2,641 patients undergoing TEVAR for CTBAD were deemed suitable to be included for quantitative analysis. The remaining 49 articles were deemed unsuitable, predominantly for lacking adequate reporting of outcomes of interest. Two articles were excluded for reporting outcomes for branched/fenestrated endovascular repair for CTBAD.

Of the 48 included studies, nine were prospective and the remaining 39 were retrospective cohort studies (Table 1). Included studies had varying cohort sizes from 10 to 208 patients. Definition of chronicity varied between the included studies, however, the majority using greater than 2 weeks after the onset of symptoms or diagnosis to define a CTBAD. The majority of included studies reported outcomes for CTBAD DeBakey type III (type IIIa, IIIb or both), while 13 studies reported outcomes for mixed cohorts of residual type I and III CTBAD patients. The indication for intervention for CTBAD varied amongst the included studies (Table S1). The majority of the included studies included mixed cohorts of both complicated and uncomplicated CTBAD. The weighted mean follow-up period of all included studies was 33.8 months.

\section{Baseline characteristics}

Overall, the weighted pooled age of all patients was 60.5 years. The entire patient population was comprised of $76.7 \%$ males. The majority of patients had a history of hypertension $(89.4 \%)$. Only a fraction of the included patients had a history of diabetes $(10.4 \%)$, prior cerebrovascular accident (CVA) $(5.6 \%)$ or renal insufficiency $(11.3 \%)$. Pooled interval between diagnosis and endovascular repair of CTBAD was 20.6 months $(95 \%$ CI, 14.5-25.8). Approximately one third of the patient population had undergone prior cardiac or open aortic surgery $(29.2 \%)$. Other patient baseline characteristics are seen in Table S2. History of peripheral vascular disease, congestive heart failure and other comorbidities were poorly reported across the included studies.

A number of different endoprostheses were used across the included studies (Table S3). These included the Zenith TX1 and TX2 (Cook Medical Incorporated, Bloomington, Indiana, USA), Talent and Valiant Captiva (Medtronic Incorporated, Santa Rosa, California, USA), TAG and cTAG (W.L Gore \& Associates, Newark, Delaware, USA) and Relay endoprostheses (Terumo Aortic, Tokyo, Japan). 


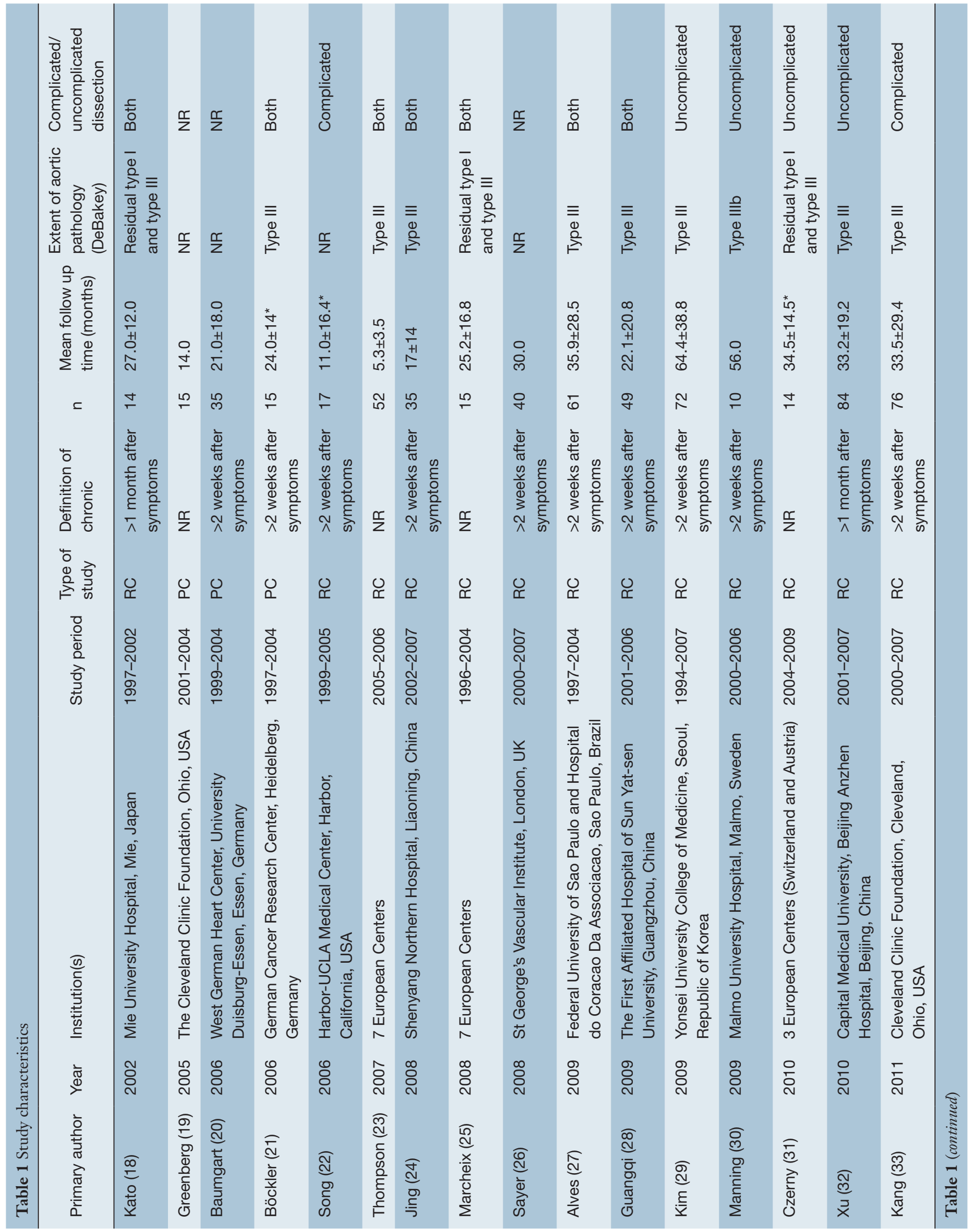




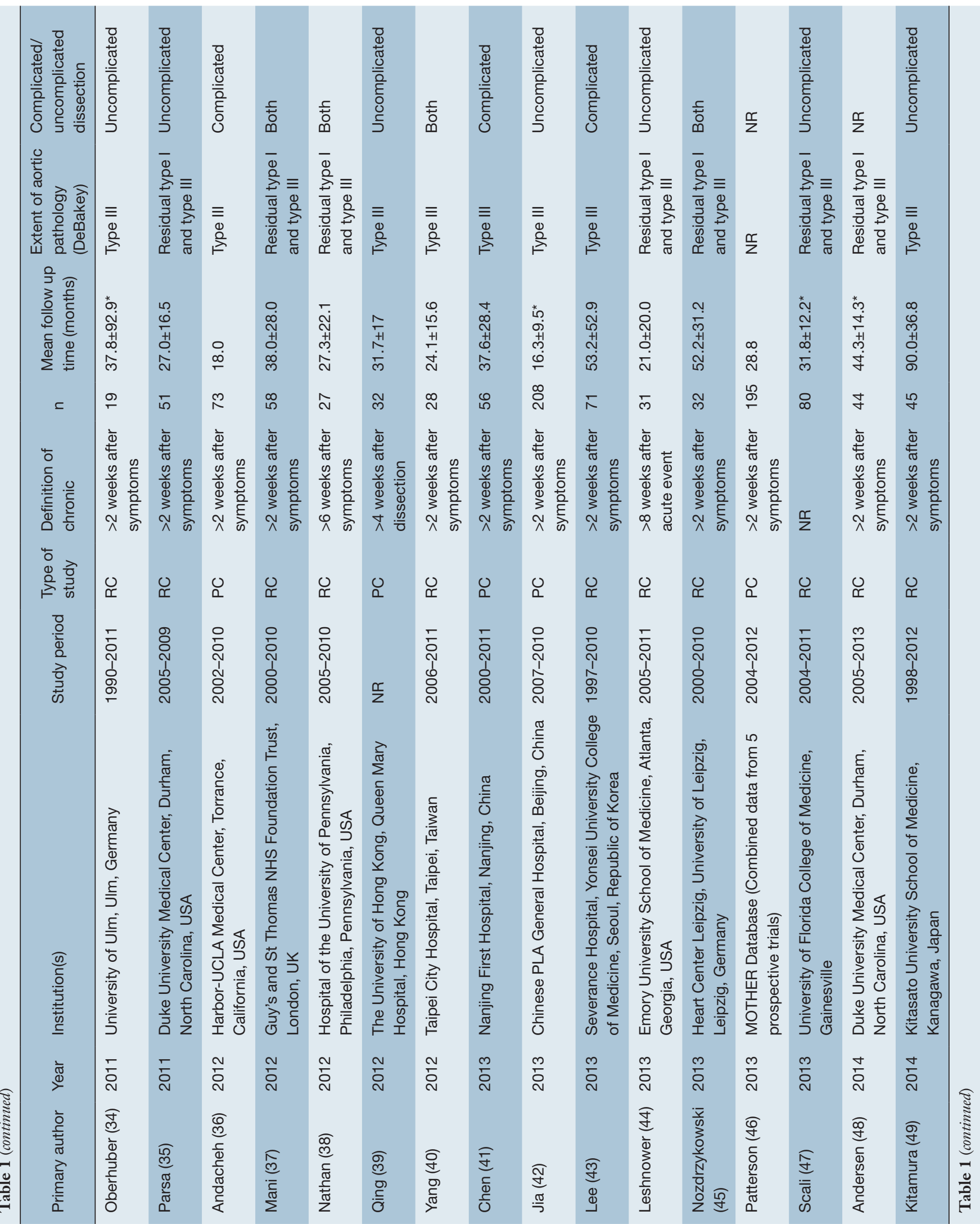




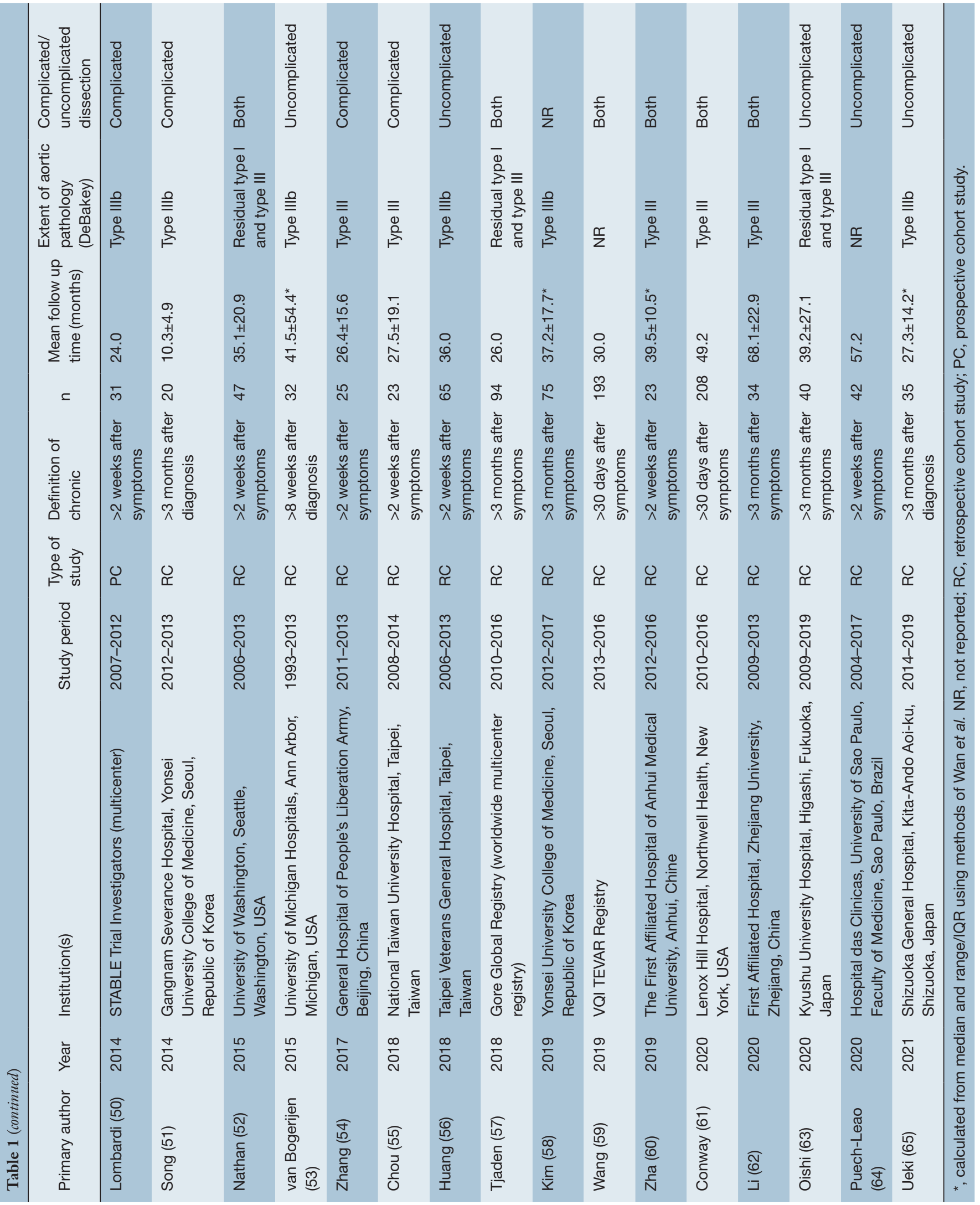


Operative details were poorly reported across the included studies, which limited the statistical analysis. Left subclavian artery coverage was performed in $38.6 \%$ of patients $(95 \%$ CI, 28.9-48.7). Revascularization of the left subclavian artery in these instances of left subclavian coverage was poorly reported. The pooled weighted technical success was high at $99.0 \%$ (95\% CI, 97.7-99.8) and the need for open surgical conversion was low at $0.4 \%$ (95\% CI, 0.01-1.3). The usage of spinal drainage peri- or intra-operatively was poorly reported. Other operative details including number of stents used per patient and stent dimensions are summarized in Table S3.

\section{Early post-operative outcomes}

All 48 included papers reported early (<30 days) mortality rates. The weighted pooled estimate of early all-cause mortality was $1.6 \%$ (95\% CI, 0.8-2.6; $\mathrm{I}^{2}=44 \%$ ) (Table 2). Pooled rates for early aortic-related mortality were low (0.5\%; 95\% CI, 0.1-1.3; I $\left.\mathrm{I}^{2}=35 \%\right)$. Twenty-five studies reported rates for retrograde type $\mathrm{A}$ dissection and the pooled estimate for this outcome was 1.4\% (95\% CI, $\left.0.6-2.5 ; \mathrm{I}^{2}=15 \%\right)$. The weighted pooled rates for CVA and SCI were $1.1 \%\left(95 \% \mathrm{CI}, 0.5-1.7 ; \mathrm{I}^{2}=2 \%\right)$ and $0.9 \%$ (95\% CI, $0.3-1.6 ; \mathrm{I}^{2}=16 \%$ ), respectively. The rate of renal insufficiency was 3.2\% (95\% CI, 1.3-5.7; $\left.\mathrm{I}^{2}=68 \%\right)$. Other early post-operative outcomes were inconsistently reported, such as length of intensive care unit stay/length of hospital stay, pneumonia, infection and access site complications. Rates of endoleaks were inconsistently reported and therefore a meta-analysis for this outcome was not performed. Data regarding reported rates of endoleaks are summarized in Table S4. Other early post-operative outcomes are summarized in Table 2.

\section{Late outcomes}

Late follow-up all-cause mortality was reported in almost all of the included studies (46/48). Weighted pooled estimate for late all-cause and aortic-related mortality were $8.0 \%$ (95\% CI, 5.8-10.5; $\mathrm{I}^{2}=72 \%$ ) and 2.4\% (95\% CI, 1.3-3.6; $\mathrm{I}^{2}=29 \%$ ), respectively (Table 3). Reintervention mortality rate was low at $0.1 \%\left(95 \% \mathrm{CI}, 0.0-0.6 ; \mathrm{I}^{2}=0 \%\right)$. Rates of retrograde type $\mathrm{A}$ aortic dissection and aortic rupture were also low at $0.8 \%$ (95\% CI, 0.2-1.6.; $\left.\mathrm{I}^{2}=0 \%\right)$ and $1.2 \%(95 \%$ CI, 0.3-2.4; $\mathrm{I}^{2}=31 \%$ ), respectively. Rates for CVA and SCI were inconsistently reported for late follow-up, however, when reported these rates were low (between 0 and $3.2 \%$ ).
Rates of endovascular reintervention were $10.1 \%$ (95\% CI, $6.8-13.9 ; \mathrm{I}^{2}=71 \%$ ) and open surgical reintervention surgical reintervention were $6.7 \%$ (95\% CI, 4.0-10.0; $\left.\mathrm{I}^{2}=74 \%\right)$. Pooled estimate of complete false lumen thrombosis for 823 patients across 23 studies was 54.0\% (95\% CI, 42.0-65.7; $\left.\mathrm{I}^{2}=92 \%\right)$. The reported rates of complete false lumen thrombosis varied significantly across studies shown by the high heterogeneity result. Complete false-lumen thrombosis was also inconsistently defined in the included studies as either complete thrombosis along the length of the stent graft or the entire length of the thoracic/thoracoabdominal aortic dissection. Again, reported rates of endoleaks were inconsistently reported for late follow-up (Table S4). Other late outcomes of interest, such as rates of stent graft induced new entry tears, were inconsistently reported among the included studies.

\section{Survival}

Aggregation of overall survival was performed from 23 of the included studies $(20,26-28,32,33,35,37,38,40,42,45-$ 49,52-54,56,62-64). Overall survival rates at 1-, 2-, 3-, 4- and 5-year were $91.5 \%, 88.5 \%, 84.7 \%, 82.2 \%$ and $77.7 \%$, respectively (Figure 2). At 10 -year post TEVAR for CTBAD the overall survival rate was $56.3 \%$. Aortarelated survival was aggregated from six included studies $(29,35,42,46,54,62)$. Aorta-related survival rates were $97.2 \%, 95.8 \%, 94.9 \%, 94.4 \%, 94.4 \%$ and $90.9 \%$ at $1-, 2-$, 3-, 4-, 5- and 10-year, respectively (Figure 3).

\section{Freedom from re-intervention}

Kaplan-Meier curves reporting rates of freedom from reintervention were available in 10 of the included studies for aggregation $(29,33-35,46-49,63,64)$. Rates of freedom from re-intervention at 1-, 2-, 3-, 4- and 5-year were $85.2 \%$, $80.6 \%, 79.2 \%, 77.6 \%$, and $73.3 \%$, respectively (Figure 4). At 10 -year post TEVAR for CTBAD freedom from reintervention was $55.1 \%$.

\section{Discussion}

CTBAD remains a challenging pathology with regards to the optimal management strategy. TEVAR has undergone considerable evolution and expansion over the past two decades and provides a less invasive procedure compared to open surgery with promising results. However, the role of TEVAR in CTBAD remains controversial with most 


\begin{tabular}{|c|c|c|c|c|}
\hline Parameter & Events/total & Number of studies & Weighted pooled estimate (\%) $(95 \% \mathrm{Cl})$ & Heterogeneity $I^{2}(\%)$ \\
\hline All-cause mortality & $75 / 2,641$ & 48 & $1.6(0.8-2.6)$ & 44 \\
\hline Aortic-related mortality & $32 / 2,000$ & 39 & $0.5(0.1-1.3)$ & 35 \\
\hline Retrograde TAAD & $32 / 1,299$ & 25 & $1.4(0.6-2.5)$ & 15 \\
\hline Cerebrovascular accident & $43 / 2,051$ & 42 & $1.1(0.5-1.7)$ & 2 \\
\hline Spinal cord injury & $42 / 2,017$ & 40 & $0.9(0.3-1.6)$ & 16 \\
\hline Rupture & $11 / 880$ & 20 & $0.5(0.1-1.3)$ & 0 \\
\hline Renal insufficiency & $42 / 1,125$ & 23 & $3.2(1.3-5.7)$ & 68 \\
\hline
\end{tabular}

\begin{tabular}{lllll} 
Table 3 Late outcomes (>30 days) & \multicolumn{1}{l}{} \\
\hline Parameter & Events/total & Number of studies & Weighted pooled estimate (\%) $(95 \%$ Cl) & Heterogeneity I ${ }^{2}(\%)$ \\
\hline All-cause mortality & $219 / 2,322$ & 46 & $8.0(5.8-10.5)$ & 72 \\
\hline Aortic-related mortality & $51 / 1,494$ & 32 & $2.4(1.3-3.6)$ & 29 \\
Reintervention-related mortality & $8 / 949$ & 20 & $0.1(0.0-0.6)$ & 0 \\
\hline Retrograde TAAD & $18 / 1,141$ & 21 & $0.8(0.2-1.6)$ & 0 \\
Rupture & $26 / 1,179$ & 21 & $1.2(0.3-2.4)$ & 31 \\
Endovascular reintervention & $136 / 1,280$ & 29 & $10.1(6.8-13.9)$ & 71 \\
Surgical reintervention & $132 / 1,433$ & 29 & $6.7(4.0-10.0)$ & 74 \\
\hline Complete false lumen thrombosis & $478 / 873$ & 23 & $54.0(42.0-65.7)$ & 92 \\
\hline Cl, confidence interval; TAAD, type A aortic dissection. & & \\
\end{tabular}

institutions favoring optimal medical therapy as the primary management strategy for uncomplicated cases. The aim of this systematic review was to provide an updated and comprehensive review of the available evidence regarding the safety and efficacy of TEVAR in patients with CTBAD.

The pooled in-hospital all-cause and aortic-related mortality rates in this present study were low at $1.6 \%$ and $0.5 \%$, respectively. On the contrary, some of the included studies reported higher mortality rates, such as the study by Puech-Leao et al., which reported an in-hospital mortality rate of $12.0 \%$ (64). However, this was a small cohort of patients (37), and the majority of the deaths were related to retrograde type A dissections. The mortality rates in this present study also highlight the difference between outcomes for acute and chronic aortic dissections undergoing TEVAR, especially in the early post-operative period. A recent meta-analysis assessing TEVAR in type B aortic dissections reported in-hospital all-cause and aorticrelated mortality rates of $9.4 \%$ and $5.6 \%$, respectively, during the acute phase of the disease (66). Interestingly, in that same study during late follow-up the all-cause mortality rate for TEVAR in acute phase dissection were similar to this present study, reported at $10.0 \%$.

Important causes of early mortality after TEVAR are aortic rupture and retrograde type A dissection. It has been hypothesized that proximal bare springs or barbs for fixation of the stent in some models of endoprosthesis can increase the risk of retrograde dissection, along with guidewire manipulation and device delivery sheaths (67). The incidence of both rupture and retrograde dissection were low in the present review, at $0.5 \%$ and $1.4 \%$, respectively. This rate of $1.4 \%$ for retrograde type A dissection compares 


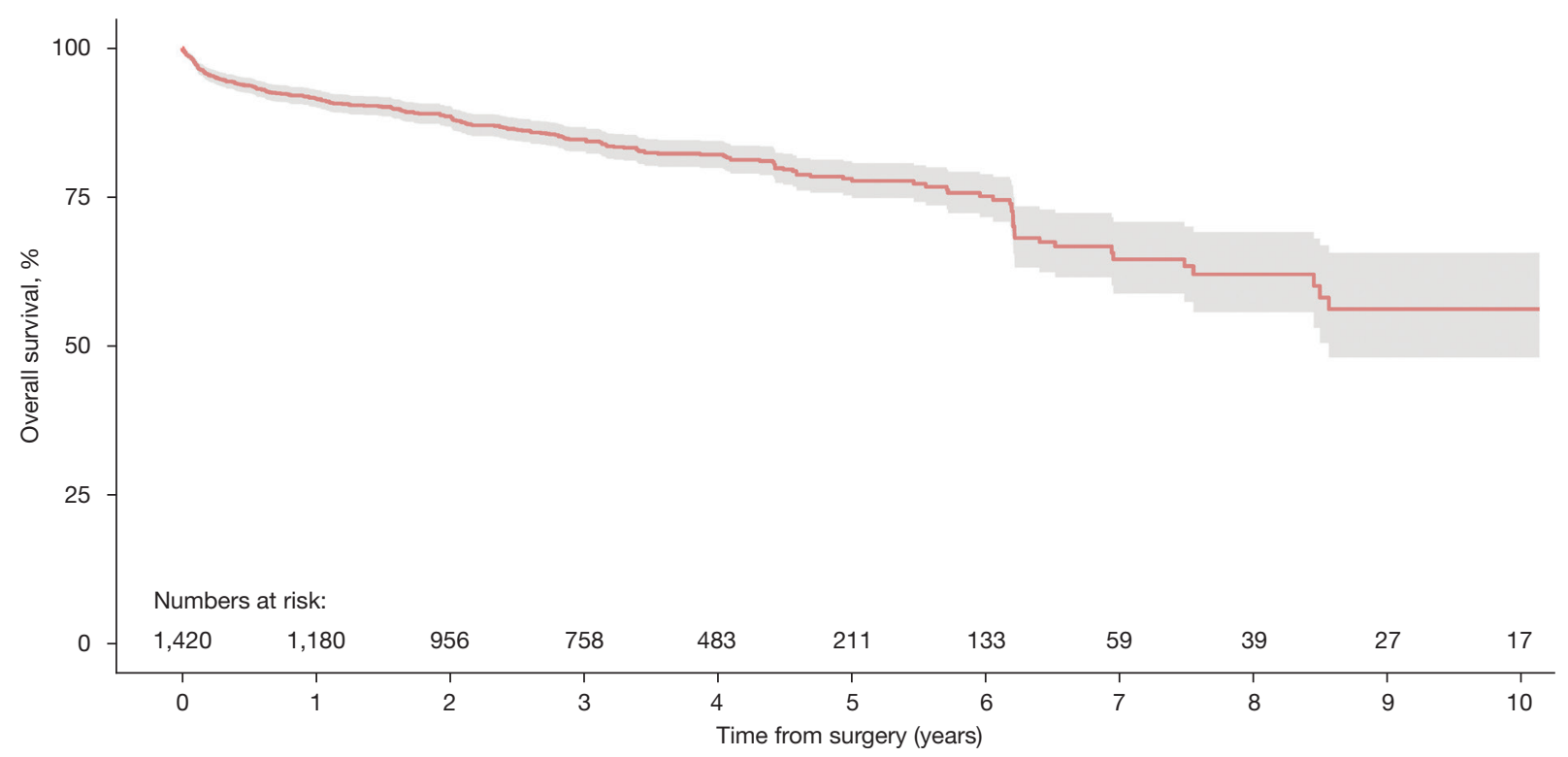

Figure 2 Aggregated overall survival after TEVAR in CTBAD (shaded region represents 95\% CI). TEVAR, thoracic endovascular aortic repair; CTBAD, chronic type B aortic dissection.

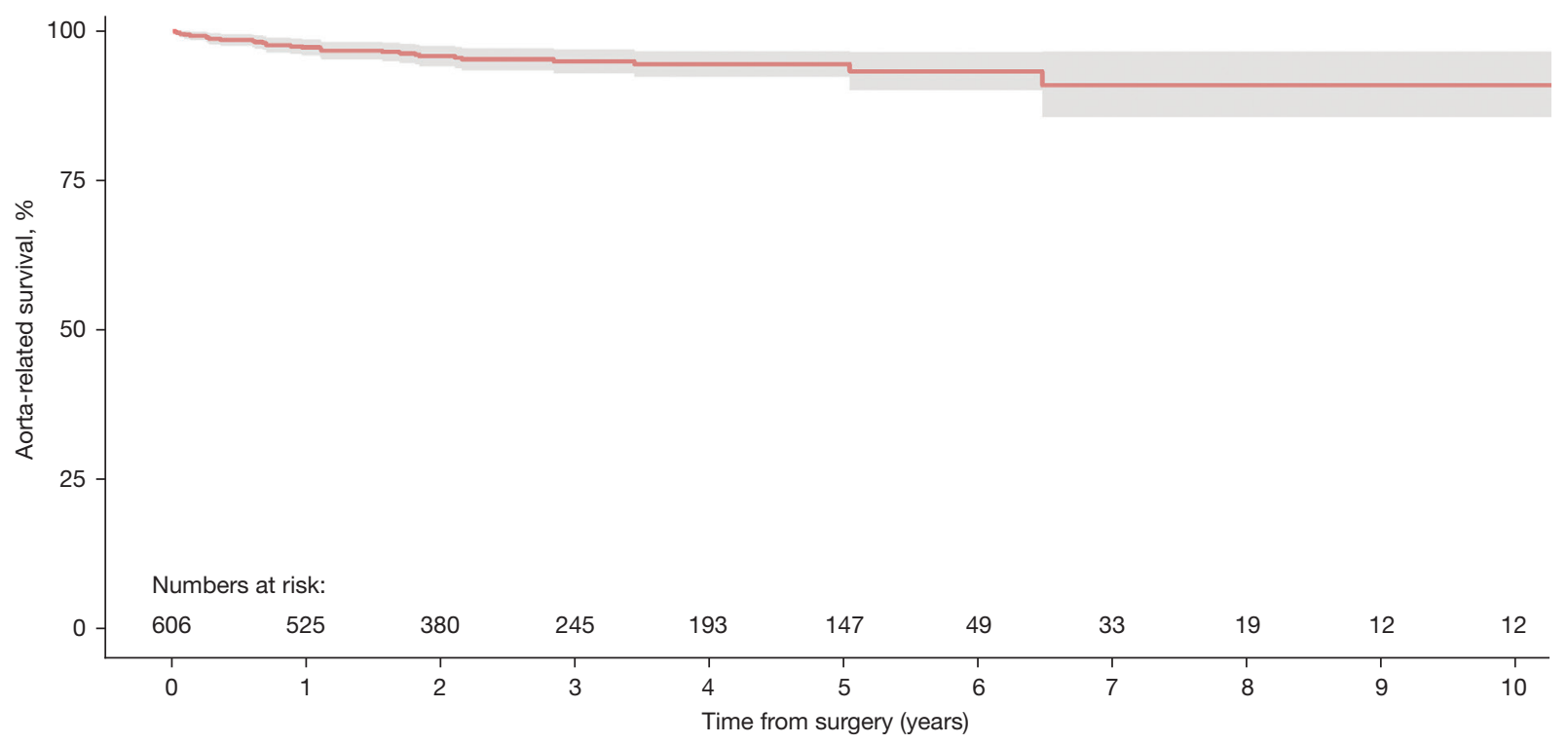

Figure 3 Aggregated aorta-related survival after TEVAR in CTBAD (shaded region represents 95\% CI). TEVAR, thoracic endovascular aortic repair; CTBAD, chronic type B aortic dissection.

similarly to the $1.33 \%$ in the European Registry on Endovascular Aortic Repair complications and favorable to the $3.17 \%$ reported in a recent single center study of over 850 patients (68). The rates of CVA and SCI in the present study were $1.1 \%$ and $0.9 \%$ respectively. This is lower than the rates reported by Boufi et al., who when comparing
TEVAR to open surgery for CTBAD reported CVA and SCI rates of $2.7 \%$ and $2.2 \%$, respectively, for TEVAR and $4.5 \%$ and $5.0 \%$, respectively, for open surgery (69).

One main concern regarding TEVAR for CTBAD is its durability and the requirement for subsequent reintervention. In the present study, the rate of secondary 


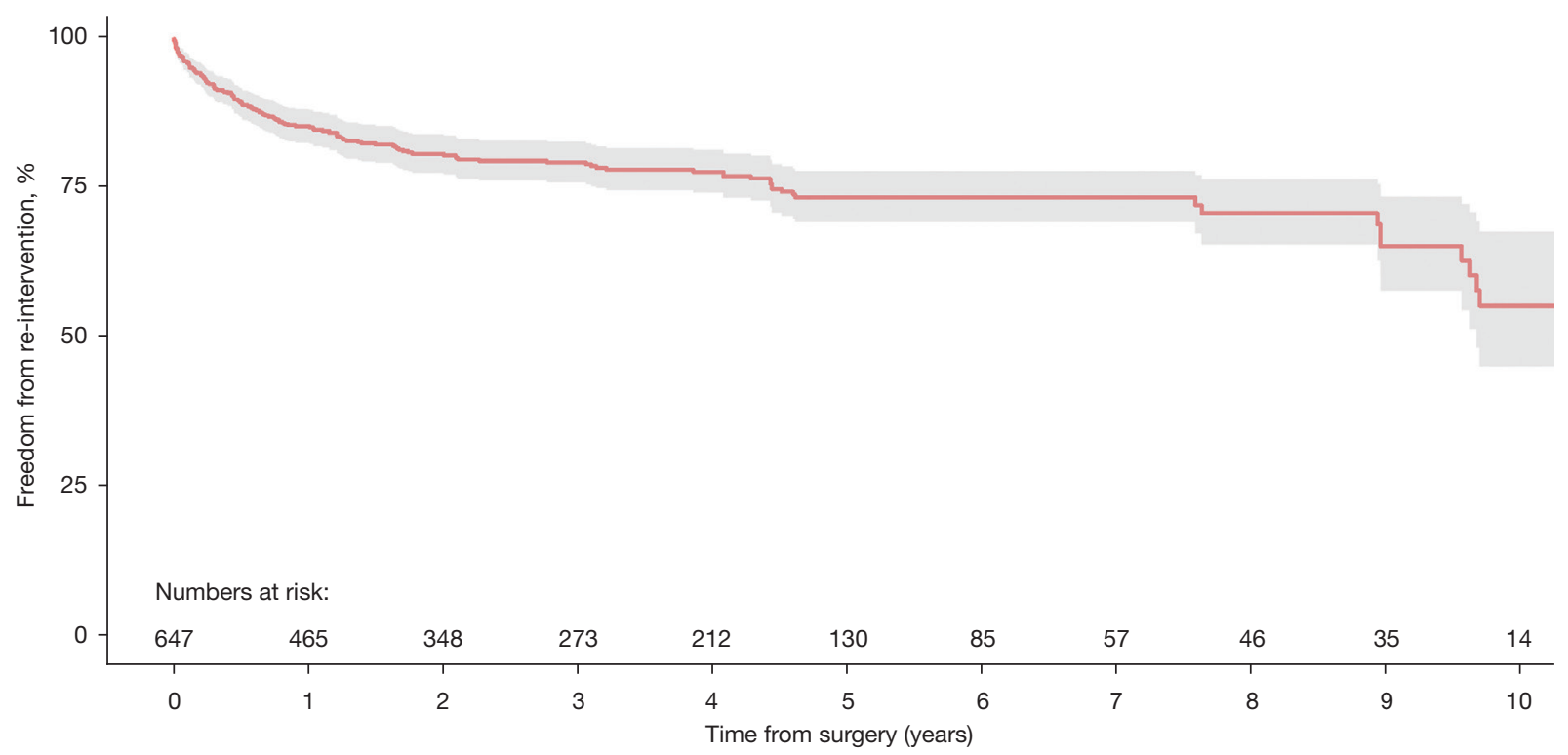

Figure 4 Aggregated freedom from re-intervention after TEVAR in CTBAD (shaded region represents 95\% CI). TEVAR, thoracic endovascular aortic repair; CTBAD, chronic type B aortic dissection.

endovascular intervention was $10.1 \%$ and $6.7 \%$ for open surgical reintervention. These are comparable to a recent review of over 5,000 patients (both acute and chronic cases) that reported rates of $12.5 \%$ and $6.1 \%$ for endovascular and surgical reintervention, respectively (66). However, another systematic review reported varying rates of endovascular reintervention from 4.3 to $47.4 \%$ after TEVAR for CTBAD (70).

It has previously been reported in the literature that TEVAR has higher rates of 1-year survival when compared to open surgery (90-93\% vs. $79-81 \%$, respectively), however, at 3-year follow-up this survival benefit was lost (TEVAR $67 \%$ vs. open surgery $71 \%$ ) (71). However, a recent meta-analysis reported that there was no benefit of one technique over the other regarding 1- and 3-year survival (69). In comparison, the results of the current study report a similar 1-year survival rate for TEVAR at $91.5 \%$, however, the 3 -year survival rate is considerably higher at $84.7 \%$. When compared to medical therapy alone, the INSTEAD trial reported improved 5-year aorta-specific survival and delayed disease progression for TEVAR with optimal medical treatment for patients with uncomplicated CTBAD (72). This is the only randomized control trial to date comparing TEVAR to optimal medical therapy for uncomplicated CTBAD [the TEVAR cohort of which is included in this present study in the larger MOTHER database (46)].
It is known that aortic remodeling and complete thrombosis of the false lumen are important factors for positive long-term results for TEVAR in type B dissection $(26,37,43)$. In CTBAD, there is thickening of the dissection septum which progresses over time, and consequently, there is usually less aortic remodeling seen in chronic compared to acute dissections. Recently, the VIRTUE study confirmed this, reporting that when compared to acute or sub-acute patients, patients who underwent TEVAR with CTBAD had lesser degrees of aortic remodeling (73). Unfortunately, in the present study, aortic remodeling was either poorly or inconsistently reported across studies, limiting its analysis. Rates of complete false lumen thrombosis were the most consistent outcome reported across approximately half of the included studies. Even though the pooled estimate for this outcome was $54.0 \%$, the specific anatomic location where the false lumen thrombosis was complete (i.e., length of the stent graft versus entire length of dissected aorta) was poorly reported. This is lower than the $71.7 \%$ rate of complete false lumen thrombosis reported by Boufi and colleagues for TEVAR patients in CTBAD (69). To improve the future analysis of this important outcome of aortic remodeling and its link to long-term patient outcomes, guidelines and consensus reporting standards should be implemented to improve the degree of heterogeneity in reporting of this outcome in the literature.

Another important consideration when reviewing the 
available literature is the recent change in definition of chronicity for type B aortic dissections. Some studies divide type $\mathrm{B}$ dissection patients into three distinct different groups, acute ( $<2$ weeks), sub-acute ( 2 weeks to 3 months) and chronic ( $>3$ months), including a separate "subacute phase" (74). A large number of the more recent studies included in this review defined CTBAD to be greater than 3 months from diagnosis or symptom onset $(51,57,58,62,63,65)$, whereas the overall majority of studies, especially those published before 2014, used a definition of greater than 2 weeks to define chronicity. It is unclear exactly how this change in classification will affect longterm results or ideal timing for intervention, however, some studies have reported that patients treated in the sub-acute phase exhibit better early, mid- and long-term outcomes when compared to acute or chronic patients who do not need emergent intervention (62). This hypothesis however requires prospective randomized controlled trials to confirm this reported evidence in observational studies.

There are a number of important limitations to consider when interpreting the results described in this present study. As mentioned above, there were different definitions of chronicity and indications for TEVAR in CTBAD used across the included studies. There was also significant heterogeneity for some of the reported outcomes, including late all-cause mortality, endovascular and surgical reintervention rates and false lumen thrombosis rates. This could represent a number of different factors, such as different patient population or selection, differing centers with varying operator experience or the different endoprostheses used across the included studies. Studies also inconsistently reported loss to follow-up and some studies reported outcomes with high complication rates in small patient populations. The observational nature of all included studies also presents an inherent source of bias in the present study. There were also varying definitions of technical success across the included studies.

\section{Conclusions}

In summary, TEVAR provides a safe and effective treatment modality for patients with CTBAD. It can be performed with low complication rates in high volume, experienced centers. Due to the limited evidence, based mainly on retrospective cohort studies, and the heterogeneity of the reported outcomes, the optimal treatment strategy for CTBAD remains debatable. Further high quality prospective multicenter registry data and randomized control trials are required to evaluate the different treatment strategies. Consensus reporting standards with a focus on aortic remodeling are required to improve our understanding of the long-term outcomes of TEVAR in CTBAD.

\section{Acknowledgments}

Funding: None.

\section{Footnote}

Conflicts of Interest: Dr. OP provides consultation for and participates in clinical trials with Medtronic and W.L. Gore \& Associates. The other authors have no conflicts of interest to declare.

Open Access Statement: This is an Open Access article distributed in accordance with the Creative Commons Attribution-NonCommercial-NoDerivs 4.0 International License (CC BY-NC-ND 4.0), which permits the noncommercial replication and distribution of the article with the strict proviso that no changes or edits are made and the original work is properly cited (including links to both the formal publication through the relevant DOI and the license). See: https://creativecommons.org/licenses/by-nc-nd/4.0/.

\section{References}

1. Giugliano G, Spadera L, De Laurentis M, et al. Chronic aortic dissection: still a challenge. Acta Cardiol 2009;64:653-63.

2. Nienaber CA, Divchev D, Palisch H, et al. Early and late management of type $\mathrm{B}$ aortic dissection. Heart 2014;100:1491-7.

3. McGee EC Jr, Pham DT, Gleason TG. Chronic descending aortic dissections. Semin Thorac Cardiovasc Surg 2005;17:262-7.

4. Karthikesalingam A, Holt PJ, Hinchliffe RJ, et al. The diagnosis and management of aortic dissection. Vasc Endovascular Surg 2010;44:165-9.

5. Elsayed RS, Cohen RG, Fleischman F, et al. Acute Type A Aortic Dissection. Cardiol Clin 2017;35:331-45.

6. Onitsuka S, Akashi H, Tayama K, et al. Long-term outcome and prognostic predictors of medically treated acute type B aortic dissections. Ann Thorac Surg 2004;78:1268-73.

7. Tsai TT, Evangelista A, Nienaber CA, et al. Long- 
term survival in patients presenting with type A acute aortic dissection: insights from the International Registry of Acute Aortic Dissection (IRAD). Circulation 2006;114:I350-6.

8. Oda T, Minatoya K, Sasaki H, et al. Surgical Indication for Chronic Aortic Dissection in Descending Thoracic and Thoracoabdominal Aorta. Circ Cardiovasc Interv 2017;10:e004292.

9. Burke CR, Bavaria JE. The Role of Thoracic Endovascular Repair in Chronic Type B Aortic Dissection. Semin Thorac Cardiovasc Surg 2020;32:21-4.

10. Spanos K, Kölbel T. Role of Endoluminal Techniques in the Management of Chronic Type B Aortic Dissection. Cardiovasc Intervent Radiol 2020;43:1808-20.

11. Cho JW, Choo SJ, Lee CH, et al. A 10-year study of surgical results of descending aorta aneurysm repair following chronic aortic dissection. J Vasc Surg 2020;72:1288-97.

12. Crawford ES. The diagnosis and management of aortic dissection. JAMA 1990;264:2537-41.

13. Riambau V, Böckler D, Brunkwall J, et al. Editor's Choice - Management of Descending Thoracic Aorta Diseases: Clinical Practice Guidelines of the European Society for Vascular Surgery (ESVS). Eur J Vasc Endovasc Surg 2017;53:4-52.

14. Moher D, Liberati A, Tetzlaff J, et al. Preferred reporting items for systematic reviews and meta-analyses: the PRISMA statement. BMJ 2009;339:b2535.

15. Wan $X$, Wang $W$, Liu J, et al. Estimating the sample mean and standard deviation from the sample size, median, range and/or interquartile range. BMC Med Res Methodol 2014;14:135.

16. Higgins JP, Thompson SG, Deeks JJ, et al. Measuring inconsistency in meta-analyses. BMJ 2003;327:557-60.

17. Guyot P, Ades AE, Ouwens MJ, et al. Enhanced secondary analysis of survival data: reconstructing the data from published Kaplan-Meier survival curves. BMC Med Res Methodol 2012;12:9.

18. Kato N, Shimono T, Hirano T, et al. Midterm results of stent-graft repair of acute and chronic aortic dissection with descending tear: the complication-specific approach. J Thorac Cardiovasc Surg 2002;124:306-12.

19. Greenberg RK, O'Neill S, Walker E, et al. Endovascular repair of thoracic aortic lesions with the Zenith TX1 and TX2 thoracic grafts: intermediate-term results. J Vasc Surg 2005;41:589-96.

20. Baumgart D, Eggebrecht H, Herold U, et al. Underlying aortic pathology and clinical health status determine success of endovascular stent-grafting for descending thoracic aortic disease. Catheter Cardiovasc Interv 2006;67:527-34.

21. Böckler D, Schumacher H, Ganten M, et al. Complications after endovascular repair of acute symptomatic and chronic expanding Stanford type B aortic dissections. J Thorac Cardiovasc Surg 2006;132:361-8.

22. Song TK, Donayre CE, Walot I, et al. Endograft exclusion of acute and chronic descending thoracic aortic dissections. J Vasc Surg 2006;43:247-58.

23. Thompson M, Ivaz S, Cheshire N, et al. Early results of endovascular treatment of the thoracic aorta using the Valiant endograft. Cardiovasc Intervent Radiol 2007;30:1130-8.

24. Jing QM, Han YL, Wang XZ, et al. Endovascular stentgrafts for acute and chronic type $\mathrm{B}$ aortic dissection: comparison of clinical outcomes. Chin Med J (Engl) 2008;121:2213-7.

25. Marcheix B, Rousseau H, Bongard V, et al. Stent grafting of dissected descending aorta in patients with Marfan's syndrome: mid-term results. JACC Cardiovasc Interv 2008;1:673-80.

26. Sayer D, Bratby M, Brooks M, et al. Aortic morphology following endovascular repair of acute and chronic type B aortic dissection: implications for management. Eur J Vasc Endovasc Surg 2008;36:522-9.

27. Alves CM, da Fonseca JH, de Souza JA, et al. Endovascular treatment of type B aortic dissection: the challenge of late success. Ann Thorac Surg 2009;87:1360-5.

28. Guangqi C, Xiaoxi L, Wei C, et al. Endovascular repair of Stanford type B aortic dissection: early and midterm outcomes of 121 cases. Eur J Vasc Endovasc Surg 2009;38:422-6.

29. Kim U, Hong SJ, Kim J, et al. Intermediate to long-term outcomes of endoluminal stent-graft repair in patients with chronic type B aortic dissection. J Endovasc Ther 2009;16:42-7.

30. Manning BJ, Dias N, Ohrlander T, et al. Endovascular treatment for chronic type $\mathrm{B}$ dissection: limitations of short stent-grafts revealed at midterm follow-up. J Endovasc Ther 2009;16:590-7.

31. Czerny M, Roedler S, Fakhimi S, et al. Midterm results of thoracic endovascular aortic repair in patients with aneurysms involving the descending aorta originating from chronic type B dissections. Ann Thorac Surg 2010;90:90-4.

32. Xu SD, Huang FJ, Yang JF, et al. Early and midterm results of thoracic endovascular aortic repair of chronic 
type B aortic dissection. J Thorac Cardiovasc Surg 2010;139:1548-53.

33. Kang WC, Greenberg RK, Mastracci TM, et al. Endovascular repair of complicated chronic distal aortic dissections: intermediate outcomes and complications. J Thorac Cardiovasc Surg 2011;142:1074-83.

34. Oberhuber A, Winkle P, Schelzig H, et al. Technical and clinical success after endovascular therapy for chronic type B aortic dissections. J Vasc Surg 2011;54:1303-9.

35. Parsa CJ, Williams JB, Bhattacharya SD, et al. Midterm results with thoracic endovascular aortic repair for chronic type B aortic dissection with associated aneurysm. J Thorac Cardiovasc Surg 2011;141:322-7.

36. Andacheh ID, Donayre C, Othman F, et al. Patient outcomes and thoracic aortic volume and morphologic changes following thoracic endovascular aortic repair in patients with complicated chronic type B aortic dissection. J Vasc Surg 2012;56:644-50; discussion 650.

37. Mani K, Clough RE, Lyons OT, et al. Predictors of outcome after endovascular repair for chronic type B dissection. Eur J Vasc Endovasc Surg 2012;43:386-91.

38. Nathan DP, Woo EY, Fairman RM, et al. Stent grafting for aneurysmal degeneration of chronic descending thoracic aortic dissections. J Vasc Surg 2012;55:963-7.

39. Qing KX, Yiu WK, Cheng SW. A morphologic study of chronic type B aortic dissections and aneurysms after thoracic endovascular stent grafting. J Vasc Surg 2012;55:1268-75; discussion 1275-6.

40. Yang CP, Hsu CP, Chen WY, et al. Aortic remodeling after endovascular repair with stainless steel-based stent graft in acute and chronic type B aortic dissection. J Vasc Surg 2012;55:1600-10.

41. Chen SL, Zhu JC, Li XB, et al. Comparison of long-term clinical outcome between patients with chronic versus acute type $\mathrm{B}$ aortic dissection treated by implantation of a stent graft: a single-center report. Patient Prefer Adherence 2013;7:319-27.

42. Jia X, Guo W, Li TX, et al. The results of stent graft versus medication therapy for chronic type B dissection. J Vasc Surg 2013;57:406-14.

43. Lee M, Lee DY, Kim MD, et al. Outcomes of endovascular management for complicated chronic type B aortic dissection: effect of the extent of stent graft coverage and anatomic properties of aortic dissection. J Vasc Interv Radiol 2013;24:1451-60.

44. Leshnower BG, Szeto WY, Pochettino A, et al. Thoracic endografting reduces morbidity and remodels the thoracic aorta in DeBakey III aneurysms. Ann Thorac Surg
2013;95:914-21.

45. Nozdrzykowski M, Etz CD, Luehr M, et al. Optimal treatment for patients with chronic Stanford type B aortic dissection: endovascularly, surgically or both?. Eur J Cardiothorac Surg 2013;44:e165-74; discussion e174.

46. Patterson B, Holt P, Nienaber C, et al. Aortic pathology determines midterm outcome after endovascular repair of the thoracic aorta: report from the Medtronic Thoracic Endovascular Registry (MOTHER) database. Circulation 2013;127:24-32.

47. Scali ST, Feezor RJ, Chang CK, et al. Efficacy of thoracic endovascular stent repair for chronic type B aortic dissection with aneurysmal degeneration. J Vasc Surg 2013;58:10-7.e1.

48. Andersen ND, Keenan JE, Ganapathi AM, et al. Current management and outcome of chronic type B aortic dissection: results with open and endovascular repair since the advent of thoracic endografting. Ann Cardiothorac Surg 2014;3:264-74.

49. Kitamura T, Torii S, Oka N, et al. Key success factors for thoracic endovascular aortic repair for non-acute Stanford type B aortic dissection. Eur J Cardiothorac Surg 2014;46:432-7; discussion 437.

50. Lombardi JV, Cambria RP, Nienaber CA, et al. Aortic remodeling after endovascular treatment of complicated type B aortic dissection with the use of a composite device design. J Vasc Surg 2014;59:1544-54.

51. Song SW, Kim TH, Lim SH, et al. Prognostic factors for aorta remodeling after thoracic endovascular aortic repair of complicated chronic DeBakey IIIb aneurysms. J Thorac Cardiovasc Surg 2014;148:925-32, 933.e1; discussion 932-3.

52. Nathan DP, Shalhub S, Tang GL, et al. Outcomes after stent graft therapy for dissection-related aneurysmal degeneration in the descending thoracic aorta. J Vasc Surg 2015;61:1200-6.

53. van Bogerijen GH, Patel HJ, Williams DM, et al. Propensity adjusted analysis of open and endovascular thoracic aortic repair for chronic type B dissection: a twenty-year evaluation. Ann Thorac Surg 2015;99:1260-6.

54. Zhang MH, Du X, Guo W, et al. Early and midterm outcomes of thoracic endovascular aortic repair (TEVAR) for acute and chronic complicated type B aortic dissection. Medicine (Baltimore) 2017;96:e7183.

55. Chou HW, Chan CY, Chang CH, et al. Comparisons of aortic remodelling and outcomes after endovascular repair of acute and chronic complicated Type B aortic dissections. Interact Cardiovasc Thorac Surg 2018;27:733-41.

56. Huang CY, Hsu HL, Chen PL, et al. The Impact of Distal 
Stent Graft-Induced New Entry on Aortic Remodeling of Chronic Type B Dissection. Ann Thorac Surg 2018;105:785-93.

57. Tjaden BL Jr, Sandhu H, Miller C, et al. Outcomes from the Gore Global Registry for Endovascular Aortic Treatment in patients undergoing thoracic endovascular aortic repair for type B dissection. J Vasc Surg 2018;68:1314-23.

58. Kim TH, Song SW, Heo W, et al. Complete Thoracic Aorta Remodeling After Endovascular Aortic Repair: A New Therapeutic Goal for Chronic DeBakey IIIb Aneurysms. Semin Thorac Cardiovasc Surg 2019;31:444-50.

59. Wang GJ, Cambria RP, Lombardi JV, et al. Thirty-day outcomes from the Society for Vascular Surgery Vascular Quality Initiative thoracic endovascular aortic repair for type B dissection project. J Vasc Surg 2019;69:680-91.

60. Zha B, Qiu P, Xie W, et al. Surgical Outcomes And Postoperative Descending Aorta Morphologic Remodeling After Thoracic Endovascular Aortic Repair For Acute And Chronic Type B Aortic Dissection. Clin Interv Aging 2019;14:1925-35.

61. Conway AM, Qato K, Nhan Nguyen Tran N, et al. Management of the Left Subclavian Artery in TEVAR for Chronic Type B Aortic Dissection. Vasc Endovascular Surg 2020;54:586-91.

62. Li DL, He YJ, Wang XH, et al. Long-term Results of Thoracic Endovascular Aortic Repair for Type B Aortic Dissection and Risk Factors for Survival. J Endovasc Ther 2020;27:358-67.

63. Oishi Y, Yamashita Y, Kimura S, et al. Preoperative distal aortic diameter is a significant predictor of late aortarelated events after endovascular repair for chronic type B aortic dissection. Gen Thorac Cardiovasc Surg 2020;68:1086-93.

64. Puech-Leao P, Estenssoro AEV, Wakassa TB, et al. Longterm Results of Endovascular Treatment of Chronic Type B Aortic Dissection by Closure of the Primary Tear. Ann Vasc Surg 2020;66:179-82.

Cite this article as: Williams ML, de Boer M, Hwang B, Wilson B, Brookes J, McNamara N, Tian DH, Shiraev T, Preventza O. Thoracic endovascular repair of chronic type B aortic dissection: a systematic review. Ann Cardiothorac Surg 2022;11(1):1-15. doi: 10.21037/acs-2021-taes-25
65. Ueki C, Tsuneyoshi H. Late Aortic Expansion After Thoracic Endovascular Aortic Repair for Chronic DeBakey IIIb Dissection. Ann Thorac Surg 2021;111:1271-7.

66. Li HL, Wu S, Chan YC, et al. Early and mid-term mortality and morbidity of contemporary international endovascular treatment for type B aortic dissection A systematic review and meta-analysis. Int J Cardiol 2020;301:56-61.

67. Dong ZH, Fu WG, Wang YQ, et al. Retrograde type A aortic dissection after endovascular stent graft placement for treatment of type B dissection. Circulation 2009;119:735-41.

68. Ma T, Dong ZH, Fu WG, et al. Incidence and risk factors for retrograde type A dissection and stent graft-induced new entry after thoracic endovascular aortic repair. J Vasc Surg 2018;67:1026-1033.e2.

69. Boufi M, Patterson BO, Loundou AD, et al. Endovascular Versus Open Repair for Chronic Type B Dissection Treatment: A Meta-Analysis. Ann Thorac Surg 2019;107:1559-70.

70. Kamman AV, de Beaufort HW, van Bogerijen GH, et al. Contemporary Management Strategies for Chronic Type B Aortic Dissections: A Systematic Review. PLoS One 2016;11:e0154930.

71. Subramanian S, Roselli EE. Thoracic aortic dissection: long-term results of endovascular and open repair. Semin Vasc Surg 2009;22:61-8.

72. Nienaber CA, Kische S, Rousseau H, et al. Endovascular repair of type $\mathrm{B}$ aortic dissection: long-term results of the randomized investigation of stent grafts in aortic dissection trial. Circ Cardiovasc Interv 2013;6:407-16.

73. VIRTUE Registry Investigators. Mid-term outcomes and aortic remodelling after thoracic endovascular repair for acute, subacute, and chronic aortic dissection: the VIRTUE Registry. Eur J Vasc Endovasc Surg 2014;48:363-71.

74. Steuer J, Björck M, Mayer D, et al. Distinction between acute and chronic type B aortic dissection: is there a subacute phase? Eur J Vasc Endovasc Surg 2013;45:627-31. 
Table S1 Indications for CTBAD endovascular repair

\begin{tabular}{ll}
\hline Primary author & Indication(s) \\
\hline Kato, 2002 & $\begin{array}{l}\text { (I) visceral or leg ischemia, aortic rupture, refractory hypertension, and/or refractory pain; (II) descending thoracic } \\
\text { aorta } 50 \mathrm{~mm} \text { or larger in diameter }\end{array}$ \\
Greenberg, 2005 & $\begin{array}{l}\text { (I) Chronic aortic dissection with aneurysm } 5 \mathrm{~cm} \text { or rapid growth; (II) life expectancy }>2 \text { years; (III) high-risk for } \\
\text { open surgical repair; (IV) absence of an uncorrectable coagulopathy; (V) absence of allergy to stainless steel or } \\
\text { polyester; (VI) absence of a serious groin infection; (VII) absence of systemic sepsis }\end{array}$ \\
Baumgart, 2006 & $\begin{array}{l}\text { (I) TAA and PAU recurrent pain; (II) enlargement of aortic diameter to more than } 5 \mathrm{~cm} \\
\text { Bocker, 2006 }\end{array}$ \\
Song, 2006 & $\begin{array}{l}\text { (I) Chronic expansive aortic dissection (CEAD) greater than } 55 \text { mm of maximum diameter } \\
\text { dissections with acute symptoms }\end{array}$ \\
Thompson, 2007 & NR \\
Jing, 2008 & $\begin{array}{l}\text { (I) Aortic rupture; (II) continued chest pain despite rigorous medical management; (III) refractory hypertension or }>5 \mathrm{~cm} \text {, or; (II) chronic } \\
\text { branch vessel ischemia; (IV) a maximum diameter of }>50 \text { mm (chronic AD) of the descending thoracic aorta or; (V) } \\
\text { documented aortic enlargement of }>1.0 \mathrm{~mm} / \text { year }\end{array}$
\end{tabular}

Marcheix, $2008 \quad$ Aneurysmal dilatation defined as diameter over 40mm and rapid aortic enlargement of more than $0.5 \mathrm{~cm}$ in 6 -month period

Sayer, $2008 \quad$ Presence of complications (rupture, acute dissection, end organ ischemia or pain), maximum short axis thoracic aortic diameter exceeding $5.5 \mathrm{~cm}$, or rapid growth of the thoracic aorta (1 cm in 6 months or local protocol).

Alves, 2009 (I) Persistent symptoms or; (II) total aortic diameter greater than $55 \mathrm{~mm}$

Guangqi, 2009 (I) Pseudo-aneurysm with diameter $5 \mathrm{~cm}$ or larger or rapid enlargement $>0.5 \mathrm{~cm}$ per year and; (II) acute symptoms

Kim, 2009 (I) Persistent or recurrent pain that was unresponsive to medical treatment; (II) dynamic obstruction; (III) aortic diameter $\geq 6 \mathrm{~cm}$; (IV) progressive enlargement of the false lumen ( $>5 \mathrm{~mm})$, or; (V) continuous false lumen leakage.

Manning, $2009 \quad$ Aneurysmal expansion of the false lumen

Czerny, 2010 (I) Median diameter DTA > or equal to $6 \mathrm{~cm}$

Xu, $2010 \quad$ (I) Type B aortic dissection confirmed by magnetic resonance angiography or computed tomographic angiography (CTA) with patent false lumen and no intramural hematoma; (II) time between onset of dissection and admission longer than 1 month; (III) arch diameter (landing zone) less than $38 \mathrm{~mm}$; (IV) adequate access route, and; (V) no aberrant right subclavian artery; $(\mathrm{V})$ distance between entry tear and opening of left subclavian artery (LSCA) more than $10 \mathrm{~mm}$; (VI) no Marfan syndrome or any suspected connective tissue diseases.

Kang, 2011 (I) Maximum aortic diameter of at least $55 \mathrm{~mm}$; (II) rapid aortic growth (10 mm/y); (III) clinical or radiographic evidence of rupture; (IV) intractable chest pain despite maximal medical therapy, and; (V) visceral, renal, or lower extremity malperfusion.

Orberhuber, 2011 (I) Maximum diameter of thoracic aorta $>6 \mathrm{~cm}$, and; (II) rapid expansion $>1 \mathrm{~cm} /$ year

Parsa, $2011 \quad$ (I) Rapid enlargement $>5 \mathrm{~mm}$ in 6 months; (II) aneurysm $>5.5 \mathrm{~cm}$; (III) saccular aneurysm $>2 \mathrm{~cm}$ protrusion beyond aortic wall

Andacheh, $2012 \quad$ (I) Aneurysmal enlargement; (II) failure of medical management; (III) perforation

Mani, 2012 (I) Aneurysmal dilatation $>5.5 \mathrm{~cm}$; (II) rapid expansion of $>1 \mathrm{~cm}$ in one year, or; (III) symptomatic disease (i.e., leaking aneurysm, back or chest pain with dilatation)

Nathan, $2012 \quad$ (I) Aneurysm $>5.5 \mathrm{~cm}$; (II) rapid aneurysmal enlargement $>5 \mathrm{~mm}$ over 6 months; (III) saccular aneurysm $>2 \mathrm{~cm}$ and; (IV) rupture

Table S1 (continued) 
Table S1 (continued)

\begin{tabular}{ll}
\hline Primary author & Indication(s) \\
\hline Qing, 2012 & $\begin{array}{l}\text { (I) Patients were categorized as having chronic type B aortic dissections (group A) if their maximum aortic } \\
\text { diameters were }<50 \mathrm{~mm} \text { and as having; (II) chronic dissections with aneurysms (group B) if their maximum aortic } \\
\text { diameters were } \geq 50 \mathrm{~mm}\end{array}$
\end{tabular}

Yang, 2012 (I) Refractory hypertension; (II) persistent or recurrent pain; (III) aneurysmal rupture; (IV) visceral or lower limb
ischemia; $(V)$ aneurysmal dilatation with aortic diameter $6.0 \mathrm{~mm}$

Chen, 2013 Descending thoracic aorta $\geq 40 \mathrm{~mm}$ in diameter at onset of aortic dissection with complications requiring surgical intervention, including visceral or leg ischemia, aortic rupture, refractory hypertension, refractory pain, or growth of ulcer-like projections.

Jia, 2013

(I) Patients who were diagnosed as having uncomplicated type B aorta dissection; (II) patients who were at least 20 years old but were younger than 80 years, and; (III) patients who were able to cooperate with the study procedure and provided written informed consent

Lee, 2013 (I) Rapid enlargement of the aorta or aortic diameter $>55 \mathrm{~mm}$; (II) persistent pain; (III) clinical or radiological malperfusion; (IV) rupture

Leshnower, $2013 \quad$ (I) A maximum aortic diameter $5.5 \mathrm{~cm}$ or greater; (II) rapid aortic growth of $5 \mathrm{~mm}$ or greater over a 6 -month period.

Nozdrzykowski, 2013 (I) Enlarged aortic diameter; (II) impending rupture; (III) end-organ malperfusion, or; (IV) recurrent pain

Patterson, $2013 \quad$ Varied across the included trials in the MOTHER Database

Scali, 2013 Maximal thoracic aneurysm diameter $\geq 6.0 \mathrm{~cm}$ or documented growth rate $\geq 1.0 \mathrm{~cm}$ on serial centreline computed tomography (CTA) measurements over 12 months

Andersen, $2014 \quad$ For elective: (I) aneurysmal degeneration with an absolute aortic diameter of $\geq 5.5 \mathrm{~cm}$; (II) rapid aneurysm enlargement ( $>5 \mathrm{~mm}$ in 6 months); (III) saccular aneurysm protruding $\geq 2 \mathrm{~cm}$ beyond the aortic wall; For nonelective: (I) symptomatic aneurysm with impending rupture; (II) aorto-esophageal fistula; (III) ruptured aneurysm; (IV) dynamic iliofemoral malperfusion

Kitamura, $2014 \quad$ NR

Lombardi, $2014 \quad$ (I) Branch vessel obstruction/compromise; (II) impending rupture; (III) resistant hypertension; (IV) persistent pain/ symptoms; $(V)$ or aortic growth $>5 \mathrm{~mm}$ in 3 months (or transaortic diameter $>40 \mathrm{~mm}$

Song, $2014 \quad$ Newly developed, continuing back pain, and aneurysmal degeneration (maximal thoracic aneurysm diameter 5.5 $\mathrm{cm}$ or a documented growth rate of $0.5 \mathrm{~cm}$ within 6 months seen on serial computed tomography angiograms

Nathan, $2015 \quad$ (I) Aneurysm size $\geq 5.5 \mathrm{~cm}$; (II) Aneurysm expansion $\geq 0.5 \mathrm{~cm}$ over 6 months; (III) refractory chest pain, or; (IV) rupture

van Bogerijen, 2015 (I) Aortic enlargement (defined as maximum aortic diameter $55 \mathrm{~mm}$ or rapid aortic enlargement (5 mm/year); (II) clinical or radiologic evidence of rupture; (III) acute on chronic dissection; and; (IV) distal extension of the initial dissection

Zhang, 2017

(I) Maximum aortic diameter $>55 \mathrm{~mm}$; (II) an aortic increase of $>5 \mathrm{~mm}$ within 3 months; (III) detection of organ ischemia; (IV) recurrence of other symptoms (pleural effusion, refractory pain, and resistant hypertension). Refractory pain was defined as ongoing symptoms of back and/or chest pain requiring narcotic medications in case of excellent blood pressure control.

Chou, 2018 (I) Aneurysmal degeneration with an aortic diameter $>6 \mathrm{~cm}$, or; (II) rapid aneurysmal growth $(>0.5 \mathrm{~cm}$ within 0.5 year)

Huang, 2018 (I) Progressive aneurysmal enlargement to a maximum thoracic aortic diameter of greater than $6 \mathrm{~cm}$ or an annual increase in diameter of greater than $0.5 \mathrm{~cm}$ with maximal size greater than $5 \mathrm{~cm}$ on surveillance imaging

Tjaden, $2018 \quad$ NR

Table S1 (continued) 


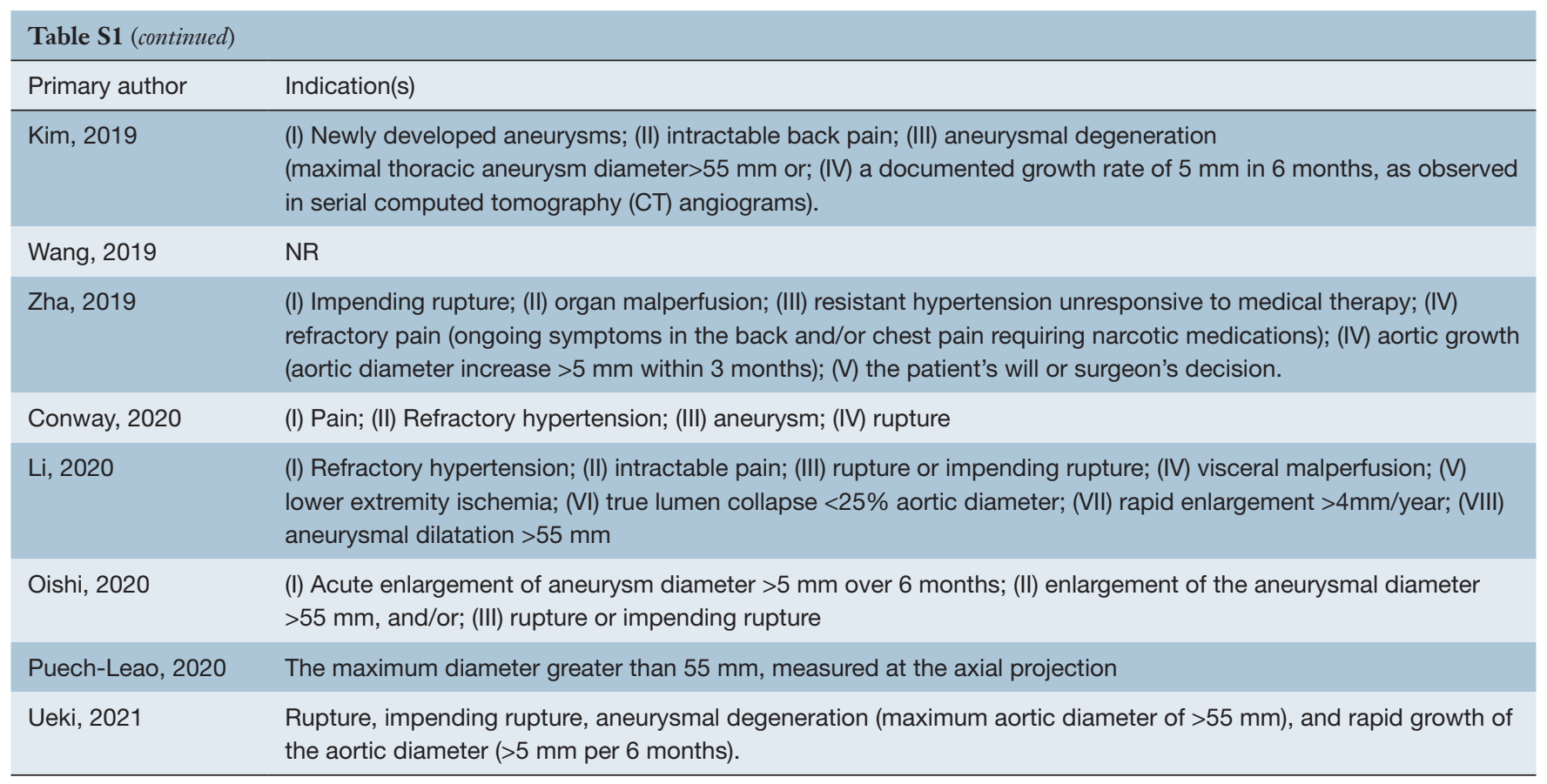


Table S2 Patient's characteristics

\begin{tabular}{|c|c|c|c|c|c|c|c|c|c|c|c|c|c|c|c|}
\hline Primary author & $\mathrm{n}$ & Age (years) & Male (\%) & $\begin{array}{l}\text { Interval between } \\
\text { diagnosis and } \\
\text { repair (months) }\end{array}$ & HTN (\%) & DM (\%) & CVA (\%) & CAD (\%) & COPD (\%) & $\begin{array}{l}\text { Smoking } \\
\text { (\%) }\end{array}$ & $\begin{array}{l}\text { Renal in- } \\
\text { sufficiency } \\
\text { (\%) }\end{array}$ & $\begin{array}{l}\text { Previous } \\
\text { cardiac/aortic } \\
\text { surgery (\%) }\end{array}$ & CTD (\%) & $\begin{array}{l}\text { Rupture } \\
(\%)\end{array}$ & $\begin{array}{l}\text { Mal-perfusion } \\
\text { syndrome (\%) }\end{array}$ \\
\hline Kato, 2002 & 14 & $61.0 \pm 14.0$ & 86.0 & $35.0 \pm 94.0$ & 64.0 & NR & 0.0 & 7.1 & NR & NR & 0.0 & 21.4 & NR & NR & NR \\
\hline Greenberg, 2005 & 15 & 54.0 & 73.0 & NR & NR & NR & NR & NR & NR & NR & NR & 26.7 & NR & NR & NR \\
\hline Baumgart, 2006 & 35 & $64.0 \pm 14.0$ & NR & NR & NR & NR & NR & NR & NR & NR & NR & NR & NR & NR & NR \\
\hline Bockler, 2006 & 15 & $59.5 \pm 10.8^{*}$ & 80.0 & NR & NR & NR & NR & NR & NR & NR & NR & 6.7 & NR & 0.0 & 6.7 \\
\hline Song, 2006 & 17 & $64.0 \pm 14.0$ & 58.8 & NR & 94.1 & 11.8 & 0.0 & 11.8 & 29.4 & NR & 29.4 & 11.8 & 0.0 & 6.3 & 6.3 \\
\hline Thompson, 2007 & 52 & $62.0 \pm 14.0$ & NR & NR & 81.0 & NR & NR & NR & NR & NR & 21.4 & 59.5 & 9.6 & NR & NR \\
\hline Jing, 2008 & 35 & $69.0 \pm 12.7$ & 85.7 & NR & 80.0 & 25.7 & 2.9 & 11.4 & 11.4 & 65.7 & 5.7 & NR & NR & 5.7 & NR \\
\hline Marcheix, 2018 & 15 & $38.7 \pm 12.8$ & 66.7 & NR & 46.7 & 6.7 & NR & NR & 40.0 & NR & 33.3 & 73.3 & 100.0 & NR & NR \\
\hline Sayer, 2008 & 40 & $66.6 \pm 11.9$ & 65.0 & NR & 67.5 & 10.0 & NR & NR & NR & 52.5 & 37.5 & 12.5 & 17.5 & NR & NR \\
\hline Alves, 2009 & 61 & $56.4 \pm 10.8$ & 77.0 & $10.5 \pm 18.0$ & 37.0 & 4.9 & NR & NR & NR & NR & 14.8 & NR & NR & NR & NR \\
\hline Guangqi, 2009 & 49 & $57.1 \pm 10.0$ & 93.9 & NR & 95.9 & NR & NR & NR & NR & NR & 6.1 & NR & 2.0 & 4.1 & 0.0 \\
\hline Kim, 2009 & 72 & $55 \pm 12.0$ & 65.3 & NR & 93.1 & 13.9 & 4.2 & 16.7 & NR & 47.2 & 5.5 & 5.6 & 2.8 & NR & NR \\
\hline Manning, 2009 & 10 & $63.0 \pm 8.5^{\star}$ & 80.0 & $26.3 \pm 17.3^{*}$ & NR & NR & NR & NR & NR & NR & NR & 10.0 & NR & NR & NR \\
\hline Czerny, 2010 & 14 & 63.0 & 79.0 & $31.5 \pm 20.0^{*}$ & 100.0 & NR & NR & NR & 68.0 & NR & NR & 21.4 & NR & NR & NR \\
\hline Xu, 2010 & 84 & $53.3 \pm 11.6$ & 82.1 & $13.9 \pm 22.0$ & 79.8 & 10.7 & NR & 11.9 & NR & 31.0 & NR & NR & 1.2 & 3.6 & NR \\
\hline Kang, 2011 & 76 & $61.5 \pm 12.5$ & 64.0 & $25.0 \pm 31.0$ & 99.0 & 10.5 & 11.8 & 38.2 & 22.4 & 42.1 & 18.4 & 22.4 & 2.6 & 1.3 & 1.3 \\
\hline Orberhuber, 2011 & 19 & $57.0 \pm 11.5^{\star}$ & 89.5 & $33.3 \pm 14.8^{*}$ & 94.7 & NR & NR & 21.1 & 21.1 & 47.4 & 31.6 & NR & 5.3 & NR & NR \\
\hline Parsa, 2011 & 51 & $57.0 \pm 12.0$ & 72.5 & $46.2 \pm 53.7$ & 94.1 & 7.8 & 5.9 & NR & 17.6 & 52.9 & 23.5 & 27.5 & NR & NR & NR \\
\hline Andacheh, 2012 & 73 & 58.0 & 71.0 & NR & NR & NR & NR & NR & NR & NR & NR & NR & NR & NR & NR \\
\hline Mani, 2012 & 58 & $66.0 \pm 11.0$ & 82.8 & $29.0 \pm 31.0$ & NR & NR & NR & NR & NR & NR & NR & 13.8 & NR & 5.2 & NR \\
\hline Nathan, 2012 & 27 & $67.5 \pm 9.6$ & 66.7 & $47.0 \pm 44.2$ & 100.0 & 11.1 & NR & 14.8 & 25.9 & NR & 11.1 & 33.3 & NR & 3.7 & 0.0 \\
\hline Qing, 2012 & 32 & NR & NR & NR & NR & NR & NR & NR & NR & NR & NR & NR & NR & NR & NR \\
\hline Yang, 2012 & 28 & $62.7 \pm 12.6$ & 85.7 & $49.8 \pm 55.8$ & 92.9 & 14.3 & 10.7 & 14.3 & 7.1 & 42.9 & 7.1 & NR & NR & NR & NR \\
\hline Chen, 2013 & 56 & $53.9 \pm 10.7$ & 78.6 & $0.8 \pm 0.2$ & 87.5 & 10.7 & 7.1 & 32.1 & 3.6 & 67.9 & 5.4 & NR & NR & NR & NR \\
\hline Jia, 2013 & 208 & $52.1 \pm 21.8$ & 74.0 & $1.0 \pm 0.2^{*}$ & 89.9 & NR & 9.6 & 12.0 & 10.8 & NR & 7.7 & NR & NR & NR & NR \\
\hline Lee, 2013 & 71 & $55.1 \pm 12.1$ & 70.4 & $26.0 \pm 42.9^{*}$ & 81.7 & 5.6 & 2.8 & 2.8 & NR & 39.4 & 4.2 & 23.9 & 7.0 & 2.8 & 9.9 \\
\hline Leshnower, 2013 & 31 & $62.0 \pm 10.0$ & 58.0 & $47.0 \pm 44.0$ & 77.0 & 9.7 & 9.7 & NR & 41.9 & NR & 6.5 & 32.3 & NR & 0.0 & NR \\
\hline $\begin{array}{l}\text { Nozdrzykowski, } \\
2013\end{array}$ & 32 & $61.2 \pm 10.0^{*}$ & 71.9 & $4.4 \pm 6.4^{*}$ & 100.0 & 28.1 & 6.2 & 18.8 & 21.9 & NR & 40.6 & 18.8 & 0.0 & 18.7 & 18.7 \\
\hline Patterson, 2013 & 195 & $63.1 \pm 11.0^{*}$ & 83.0 & NR & 83.0 & 11.3 & 3.1 & NR & 10.3 & 61.0 & 12.0 & NR & NR & NR & $N R$ \\
\hline Scali, 2013 & 80 & $60.0 \pm 13.0$ & 88.0 & $26.8 \pm 12.2^{*}$ & 95.0 & NR & 6.7 & 23.8 & 15.0 & 51.3 & 30.0 & 32.5 & 8.8 & NR & $N R$ \\
\hline Andersen, 2014 & 44 & $58.0 \pm 11.1^{*}$ & 64.0 & $31.0 \pm 50.4^{*}$ & 98.0 & 11.4 & 0.0 & 11.4 & 15.9 & 59.1 & 15.9 & 27.3 & 0.0 & NR & NR \\
\hline Kitamura, 2014 & 45 & $55.5 \pm 13.1$ & 94.3 & $16.8 \pm 33.6$ & NR & NR & NR & NR & NR & NR & 7.5 & NR & 0.0 & NR & NR \\
\hline
\end{tabular}


Table S2 (continued)

\begin{tabular}{|c|c|c|c|c|c|c|c|c|c|c|c|c|c|c|c|}
\hline Primary author & $\mathrm{n}$ & Age (years) & Male (\%) & $\begin{array}{l}\text { Interval between } \\
\text { diagnosis and } \\
\text { repair (months) }{ }^{\star *}\end{array}$ & HTN (\%) & DM (\%) & CVA (\%) & CAD (\%) & COPD (\%) & $\begin{array}{l}\text { Smoking } \\
(\%)\end{array}$ & $\begin{array}{l}\text { Renal in- } \\
\text { sufficiency } \\
(\%)\end{array}$ & $\begin{array}{l}\text { Previous } \\
\text { cardiac/aortic } \\
\text { surgery (\%) }\end{array}$ & CTD (\%) & $\begin{array}{l}\text { Rupture } \\
\text { (\%) }\end{array}$ & $\begin{array}{l}\text { Mal-perfusion } \\
\text { syndrome (\%) }\end{array}$ \\
\hline Lombardi, 2014 & 31 & $59.8 \pm 13.3$ & 77.4 & $1.4 \pm 0.8$ & 100.0 & 12.9 & 9.7 & 16.1 & 6.5 & 48.1 & 6.5 & NR & NR & NR & 58.1 \\
\hline Song, 2014 & 20 & 50.2 & 85.0 & $18.1 \pm 11.9$ & 90.0 & 5.0 & 0.0 & 5.0 & NR & 70.0 & NR & 50.0 & 5.0 & NR & NR \\
\hline Nathan, 2015 & 47 & $58.3 \pm 11.7$ & 74.5 & $53.8 \pm 50.1$ & 87.2 & NR & NR & NR & NR & NR & NR & 27.7 & 14.9 & 4.3 & NR \\
\hline $\begin{array}{l}\text { van Bogerijen, } \\
2015\end{array}$ & 32 & $69.2 \pm 10.7$ & 46.9 & $20.3 \pm 27.6$ & 93.8 & 9.4 & 3.1 & 25.0 & 25.0 & 71.0 & NR & 34.4 & 3.1 & NR & NR \\
\hline Zhang, 2017 & 25 & $65.5 \pm 10$ & 64.0 & $1.9 \pm 2.2^{*}$ & 88.0 & 16.0 & NR & 4.0 & 0.0 & 40.0 & 8.0 & NR & 0.0 & NR & NR \\
\hline Chou, 2018 & 23 & $63.9 \pm 7.9$ & 87.0 & $19.9 \pm 11.1$ & 78.2 & 8.7 & 8.7 & 17.4 & 13.0 & 26.0 & 30.4 & NR & 0.0 & 0.0 & 0.0 \\
\hline Huang, 2018 & 65 & $56.3 \pm 3.8^{\star}$ & 81.5 & $18.2 \pm 9.4^{*}$ & 95.3 & 7.7 & 7.7 & 20.0 & NR & 38.4 & 4.6 & NR & 4.6 & NR & NR \\
\hline Tjaden, 2018 & 94 & $61.0 \pm 2.8^{*}$ & 85.1 & NR & 93.6 & 6.4 & 7.4 & 20.2 & 10.6 & 50.0 & 24.5 & 22.3 & 1.1 & NR & NR \\
\hline Kim, 2019 & 75 & $58.2 \pm 12.1$ & 78.7 & $15.8 \pm 20.2^{*}$ & 82.7 & 8.0 & NR & 6.7 & 4.0 & 52.0 & 2.7 & 52.0 & 2.7 & NR & NR \\
\hline Wang, 2019 & 193 & $62.2 \pm 12.4$ & 71.5 & NR & 96.4 & 13.0 & 6.2 & 13.5 & 14.5 & 60.6 & 4.7 & 21.2 & 1.6 & 3.1 & 7.3 \\
\hline Zha, 2019 & 23 & $55.9 \pm 12.1$ & 78.3 & NR & 87.0 & 17.4 & NR & 4.3 & 8.7 & 69.6 & NR & NR & NR & NR & 8.7 \\
\hline Conway, 2020 & 208 & $65.0 \pm 12.6^{\star}$ & 72.1 & NR & 88.9 & 12.0 & 11.5 & 13.0 & 19.2 & 68.3 & 3.4 & 34.6 & 4.3 & 4.8 & NR \\
\hline Li, 2020 & 34 & $56.1 \pm 14.2$ & 82.4 & $23.0 \pm 14.4^{*}$ & 82.4 & 2.9 & 2.9 & 5.8 & 8.8 & 47.1 & 0.0 & NR & NR & 0.0 & 5.9 \\
\hline Oishi, 2020 & 40 & $66.5 \pm 11.6$ & 65.0 & NR & 97.5 & 12.5 & NR & NR & NR & 57.5 & 7.5 & 47.5 & 5.0 & NR & 0.0 \\
\hline $\begin{array}{l}\text { Puech-Leao, } \\
2020\end{array}$ & 42 & 59.1 & 76.2 & NR & NR & NR & NR & NR & NR & NR & NR & NR & 0.0 & NR & NR \\
\hline Ueki, 2021 & 35 & $63.4 \pm 2.9^{*}$ & 74.3 & $38.8 \pm 52.9^{*}$ & 94.3 & 14.3 & 5.7 & 5.7 & NR & 71.4 & 2.9 & 48.6 & NR & 11.4 & NR \\
\hline $\begin{array}{l}\text { Pooled estimate } \\
\%(95 \% \mathrm{Cl})\end{array}$ & 2,641 & $\begin{array}{l}60.5 \\
(58.1-62.8)\end{array}$ & $\begin{array}{l}76.7 \\
(73.7-79.2)\end{array}$ & $\begin{array}{l}20.6 \\
(14.5-25.8)\end{array}$ & $\begin{array}{l}89.4 \\
(85.8-92.7)\end{array}$ & $\begin{array}{l}10.4 \\
(8.9-11.9)\end{array}$ & $\begin{array}{l}5.6 \\
(4.2-7.2)\end{array}$ & $\begin{array}{l}13.8 \\
(10.8-16.9)\end{array}$ & $\begin{array}{l}15.0 \\
(11.4-18.9)\end{array}$ & $\begin{array}{l}52.7 \\
(48.1-57.4)\end{array}$ & $\begin{array}{l}11.3 \\
(8.1-14.9)\end{array}$ & $\begin{array}{l}29.2 \\
(23.8-34.8)\end{array}$ & $\begin{array}{l}4.3 \\
(1.8-7.4)\end{array}$ & - & - \\
\hline
\end{tabular}




\begin{tabular}{|c|c|c|c|c|c|c|c|c|c|}
\hline Primary author & Endoprostheses & $\begin{array}{l}\text { Number of } \\
\text { stent-grafts } \\
\text { per patient }\end{array}$ & $\begin{array}{l}\text { Stent length; } \\
\text { diameter }(\mathrm{mm})\end{array}$ & $\begin{array}{l}\text { LSA } \\
\text { coverage } \\
(\%)\end{array}$ & $\begin{array}{l}\text { Technical } \\
\text { success } \\
(\%)\end{array}$ & $\begin{array}{l}\text { Primary } \\
\text { conversion } \\
(\%)\end{array}$ & $\begin{array}{l}\text { Operative time } \\
\text { (minutes) }\end{array}$ & $\begin{array}{l}\text { CSF } \\
\text { drain (\%) }\end{array}$ & $\begin{array}{l}\text { Over-sizing } \\
(\%)\end{array}$ \\
\hline Kato, 2002 & Custom graft & NR & NR & NR & 100.0 & 0.0 & NR & NR & NR \\
\hline Greenberg, 2005 & Zenith TX1, Zenith TX2 & NR & NR & NR & NR & 0.0 & 102.0 & 82.0 & NR \\
\hline Baumgart, 2006 & Talent, GoreTAG & $1.3 \pm 0.5$ & L: $123 \pm 23, \mathrm{D}: 37 \pm 6$ & NR & 100.0 & 0.0 & NR & NR & NR \\
\hline Bocker, 2006 & Excluder, Talent, Endofit & $1.1(1-2)^{\star}$ & L: 162, D: 35.2 & 40.0 & 100.0 & 0.0 & NR & NR & NR \\
\hline Song, 2006 & AneuRx and Talent & NR & L: $188 \pm 61$ & 23.5 & NR & NR & $149.9 \pm 88.5$ & NR & NR \\
\hline Thompson, 2007 & Valiant & 1.6 & NR & NR & NR & 0.0 & NR & NR & NR \\
\hline Jing, 2008 & Talent, Zenith, Aegis & NR & L: $102.4 \pm 15.3, \mathrm{D}: 37.2 \pm 4.2$ & 5.7 & 100.0 & NR & $139 \pm 25$ & NR & NR \\
\hline Marcheix, 2008 & Talent & $1.5 \pm 0.7$ & NR & 13.3 & 66.7 & 0.0 & NR & NR & $5-10 \%$ \\
\hline Sayer, 2008 & Valiant, Talent, Excluder & 2.1 & $\begin{array}{l}\text { L: } 204 \pm 20 \mathrm{~mm} \text { proximal: } \\
32.9 \pm 1.3 \mathrm{~mm} \text {, distal: } 26.9 \pm 2.0\end{array}$ & NR & 100.0 & NR & 133.5 & NR & NR \\
\hline Alves, 2009 & Braile stent & $1.7 \pm 0.8$ & NR & NR & 98.4 & 3.3 & NR & NR & NR \\
\hline Guangqi, 2009 & Talent, Zenith, Ankura, Aegis & $1.1 \pm 0.3$ & NR & 22.4 & 77.6 & 0.0 & NR & NR & NR \\
\hline Kim, 2009 & $\begin{array}{l}\text { Custom made, separate-type modular } \\
\text { stent }\end{array}$ & NR & $\begin{array}{l}\text { L: } 83 \pm 27, \mathrm{D}: 33.8 \pm 6.8 \text { prox, } \\
33.2 \pm 6.3 \text { distal }\end{array}$ & NR & 97.2 & NR & NR & NR & NR \\
\hline Manning, 2009 & Zenith, Excluder & NR & NR & 30.0 & 100.0 & 0.0 & NR & NR & $10 \%$ \\
\hline Czerny, 2010 & Talent, Valiant, Relay & NR & L: $190(100-250)^{\star}$ & NR & 85.7 & 0.0 & NR & NR & $15-20 \%$ \\
\hline Xu, 2010 & $\begin{array}{l}\text { Talent, EndoFit, Hercules, Vasoflow, } \\
\text { Grikin }\end{array}$ & 1.11 & NR & 4.8 & NR & NR & $150 \pm 18$ & NR & NR \\
\hline Kang, 2011 & $\begin{array}{l}\text { Core TAG, Cook Zenith, Medtronic } \\
\text { Talent, Homemade }\end{array}$ & 1.9 & NR & 38.2 & 96.1 & NR & NR & 63.0 & NR \\
\hline Orberhuber, 2011 & TAG, CTAG, Captivia, Valiant, Zenith & 1.1 & NR & 47.4 & 94.7 & NR & $68(55-83)^{\star}$ & NR & NR \\
\hline Parsa, 2011 & TAG, Zenith TX2, Talent & $2.0 \pm 0.7$ & NR & 68.6 & 100.0 & NR & NR & 17.6 & NR \\
\hline Andacheh, 2012 & Talent, Valiant Captivia & NR & NR & NR & 98.6 & 0.0 & NR & 0 & NR \\
\hline Mani, 2012 & $\begin{array}{l}\text { TAG, Zenith TX2, Combined, Endofit, } \\
\text { Talent, Relay }\end{array}$ & $2(1)^{\star \star}$ & $\mathrm{L}: 220 \mathrm{~mm}(100)^{\star \star}$ & 46.6 & NR & 3.4 & $98(41)^{\star \star}$ & NR & $5-15 \%$ \\
\hline Nathan, 2012 & TAG, Zenith TX2, Talent & NR & L: $221 \pm 43$ & 51.9 & NR & NR & NR & NR & NR \\
\hline Qing, 2012 & Zenith TX2 & NR & NR & NR & 100.0 & NR & NR & NR & $15.9 \pm 7.9 \%$ \\
\hline Yang, 2012 & NR & 1.5 & NR & 71.4 & 100.0 & NR & $286.4 \pm 185.8$ & 14.3 & NR \\
\hline Chen, 2013 & Talent, Willis & $1.1 \pm 0.2$ & L: $130.8 \pm 40.6, \mathrm{D}: 36.5 \pm 4.3$ & 5.4 & 100.0 & 0.0 & NR & NR & NR \\
\hline Jia, 2013 & Valiant, Zenith TX2, Hercules & NR & NR & 36.5 & 100.0 & 4.3 & $89(35-180)^{\star}$ & NR & NR \\
\hline Lee, 2013 & SEAL, Taewoong, Valiant, Zenith TX2 & NR & NR & NR & 97.2 & 1.4 & NR & NR & NR \\
\hline Leshnower, 2013 & TAG, Talent, Zenith TX2 & 2 & L: $220 \pm 40$ & 54.8 & NR & NR & NR & 45.2 & NR \\
\hline $\begin{array}{l}\text { Nozdrzykowski, } \\
2013\end{array}$ & NR & NR & NR & NR & 100.0 & NR & NR & NR & NR \\
\hline Patterson, 2013 & Talent, Valiant, Captivia, Xcelerant & NR & NR & NR & NR & NR & NR & NR & NR \\
\hline
\end{tabular}




\begin{tabular}{|c|c|c|c|c|c|c|c|c|c|}
\hline Primary author & Endoprostheses & $\begin{array}{l}\text { Number of } \\
\text { stent-grafts } \\
\text { per patient }\end{array}$ & $\begin{array}{l}\text { Stent length; } \\
\text { diameter (mm) }\end{array}$ & $\begin{array}{l}\text { LSA } \\
\text { coverage } \\
(\%)\end{array}$ & $\begin{array}{l}\text { Technical } \\
\text { success } \\
(\%)\end{array}$ & $\begin{array}{l}\text { Primary } \\
\text { conversion } \\
(\%)\end{array}$ & $\begin{array}{l}\text { Operative time } \\
\text { (minutes) }\end{array}$ & $\begin{array}{l}\text { CSF } \\
\text { drain (\%) }\end{array}$ & $\begin{array}{l}\text { Over-sizing } \\
(\%)\end{array}$ \\
\hline Scali, 2013 & Gore TAG, Cook TX2 & NR & NR & 75.0 & 98.8 & NR & NR & 77.5 & NR \\
\hline Andersen, 2014 & NR & $2(1-2)^{\star}$ & L: $200(160-290)^{\star \star}$ & NR & 100.0 & 11.4 & NR & NR & NR \\
\hline Kitamura, 2014 & Matsui-Kitamura or handmade & NR & NR & NR & 100.0 & NR & NR & NR & NR \\
\hline Lombardi, 2014 & Zenith TX2, bare metal stent & NR & NR & NR & 100.0 & NR & NR & NR & NR \\
\hline Song, 2014 & Zenith TX2 Proform, Valiant Captivia & 1.5 & NR & 55.0 & 100.0 & 0.0 & NR & 65.0 & $10 \%-15 \%$ \\
\hline Nathan, 2015 & Zenith TX2, TAG, Talent & NR & NR & 48.9 & 97.9 & 0.0 & NR & 74.5 & $10-15 \%$ \\
\hline van Bogerijen, 2015 & TAG, TX2, Talent & NR & NR & NR & 100.0 & 0.0 & NR & 96.4 & $10 \%$ \\
\hline Zhang, 2017 & NR & 1.04 & NR & NR & 100.0 & 0.0 & $183.7 \pm 98.4$ & NR & NR \\
\hline Chou, 2018 & TAG, Zenith, Talent, Variant, Relay & NR & $\begin{array}{l}\text { D: prox } 36.7 \pm 3.9 \text {, distal } \\
33.5 \pm 4.3\end{array}$ & 8.7 & 100.0 & 0.0 & $286.4 \pm 185.5$ & 4.3 & $10-15 \%$ \\
\hline Huang, 2018 & Zenith TX2, Valiant Captivia, Gore TAG & $2(1-2)^{\star}$ & NR & 46.2 & NR & NR & $260(160-330)^{*}$ & NR & NR \\
\hline Tjaden, 2018 & TAG and CTAG & $2(1-2)^{\star}$ & L: $280(150 \text { to } 400)^{*}$ & 41.5 & NR & 0.0 & NR & NR & NR \\
\hline Kim, 2019 & NR & NR & NR & NR & NR & 4.0 & NR & NR & NR \\
\hline Wang, 2019 & Valiant, Gore CTAG, Cook TX2/Alpha & NR & NR & NR & 98.9 & NR & NR & 65.3 & NR \\
\hline Zha, 2019 & Captivia, Zenith, Ankura, Grink & NR & L: $193.35 \pm 13.6$ & 56.5 & 100.0 & NR & NR & NR & NR \\
\hline Conway, 2020 & NR & $2(1-2)^{\star}$ & NR & 80.9 & 100.0 & 0.0 & $149.5(103-219.5)^{\star *}$ & 68.7 & NR \\
\hline Li, 2020 & $\begin{array}{l}\text { Valiant, Zenith TX2, TAG, Hercules, } \\
\text { Ankura }\end{array}$ & NR & L: $165.0 \pm 25.1, \mathrm{D}: 36.0 \pm 3.3$ & 32.4 & 91.2 & NR & NR & NR & $10 \%$ \\
\hline Oishi, 2020 & $\begin{array}{l}\text { TAG, CTAG, Valiant, Zenith TX2, Relay } \\
\text { Plus }\end{array}$ & NR & $\begin{array}{l}\mathrm{L}: 10(201.2 \pm 57.9)+30 \\
(187.7 \pm 61.6)\end{array}$ & NR & 100.0 & NR & $\begin{array}{l}152.7 \pm 93.3(10 \mathrm{pts})+ \\
162.6 \pm 138.4(30 \mathrm{pts})\end{array}$ & NR & $<10 \%$ \\
\hline Puech-Leao, 2020 & NR & 1.3 & NR & 28.5 & 80.9 & NR & NR & NR & NR \\
\hline Ueki, 2021 & Gore TAG, Valiant Captivia & $2(1-3)^{\star}$ & NR & 37.1 & 100.0 & NR & $81.0(50.0-214.0)^{\star}$ & NR & NR \\
\hline $\begin{array}{l}\text { Pooled estimate \% } \\
(95 \% \mathrm{Cl})\end{array}$ & - & - & - & $\begin{array}{l}38.6 \\
(28.9-48.7)\end{array}$ & $\begin{array}{l}99.0 \\
(97.7-99.8)\end{array}$ & $\begin{array}{l}0.4(0.01- \\
1.3)\end{array}$ & - & - & - \\
\hline
\end{tabular}




\begin{tabular}{|c|c|c|}
\hline Primary author & Early post-op outcomes (\%) & Late outcomes (\%) \\
\hline Kato, 2002 & 0.0 & 0 \\
\hline Greenber, 2005 & NR & NR \\
\hline Baumgart, 2006 & NR & NR \\
\hline Bocker, 2006 & Type I: 6.7 & NR \\
\hline Song, 2006 & NR & NR \\
\hline Thompson, 2007 & Type I: 6.0, Type III: 1.9 & Type I: 12.0, Type III: 0.0 \\
\hline Jing, 2008 & 2.9 & 0 \\
\hline Marcheix, 2008 & Type I: 26.7, Type II: 6.7 & Type I: 26.7, Type III: 6.7 \\
\hline Sayer, 2008 & 5.0 & NR \\
\hline Alves, 2009 & NR & NR \\
\hline Guangqi, 2009 & Type I: 12.5 & NR \\
\hline Kim, 2009 & Type I: 8.3 & Type 1: 8.3 \\
\hline Manning, 2009 & NR & Type la: $20 \%$, Type lb: 10 \\
\hline Czerny, 2010 & Type la: 14.3 & 14.3 \\
\hline Xu, 2010 & 8.3 & NR \\
\hline Kang, 2011 & Type I: 9.2, Type IV: 1.3 & 1.3 \\
\hline Orberhuber, 2011 & Type II: 15.8 & NR \\
\hline Parsa, 2011 & NR & Type I: 7.8, Type II: 3.9 \\
\hline Andacheh, 2012 & NR & 9.6 \\
\hline Mani, 2012 & NR & NR \\
\hline Nathan, 2012 & NR & Type II: 7.4 \\
\hline Qing, 2012 & NR & 0.0 \\
\hline Yang, 2012 & Type I: 0.0, Type II: 3.6, Type III: 7.1, Type IV: 3.6 & NR \\
\hline Chen, 2013 & Type I: 1.8 & 0.0 \\
\hline Jia, 2013 & NR & 1.4 \\
\hline Lee, 2013 & NR & Type I: 12.7 \\
\hline Leshnower, 2013 & NR & 6.4 \\
\hline Nozdrzykowski, 2013 & NR & NR \\
\hline Patterson, 2013 & NR & 6.1 \\
\hline Scali, 2013 & Type I: 1.2 & 6.2 \\
\hline Andersen, 2014 & Type la: 2.0, Type lb: 2.0 & 4.0 \\
\hline Kitamura, 2014 & NR & NR \\
\hline Lombardi, 2014 & NR & NR \\
\hline Song, 2014 & Type la: 0.0, Type II: 10.0 & NR \\
\hline
\end{tabular}




\begin{tabular}{|c|c|c|}
\hline Primary author & Early post-op outcomes (\%) & Late outcomes (\%) \\
\hline Nathan, 2015 & Type la: 2.1 & NR \\
\hline van Bogerijen, 2015 & NR & Type I: 6.3, Type II: 15.6, Type III: 18.8 \\
\hline Zhang, 2017 & NR & Type I: 0.0, Type II: 4.0 \\
\hline Huang, 2018 & NR & 10.8 \\
\hline Tjaden, 2018 & NR & 12.8 \\
\hline Kim, 2019 & NR & 10.7 \\
\hline Wang, 2019 & NR & NR \\
\hline Li, 2020 & Type 1a: 8.8 & Type II: 6.1 \\
\hline Oishi, 2020 & NR & Type II: 5.0 \\
\hline Puech-Leao, 2020 & Type la: 7.1 & NR \\
\hline Ueki, 2021 & Type la: 8.5 & NR \\
\hline
\end{tabular}

